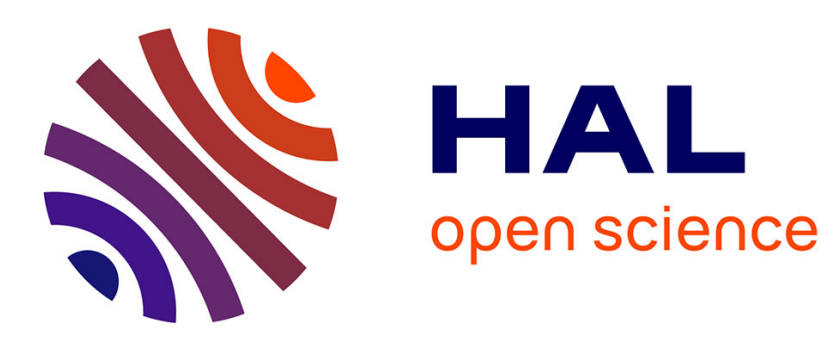

\title{
Kinetics of ordering in Ni1.50Sn ('Ni3Sn2') as revealed by the variation of the lattice parameters upon annealing
}

Andreas Leineweber, Eric Jan Mittemeijer, Michael Knapp, Carsten Baehtz

\section{To cite this version:}

Andreas Leineweber, Eric Jan Mittemeijer, Michael Knapp, Carsten Baehtz. Kinetics of ordering in Ni1.50Sn ('Ni3Sn2') as revealed by the variation of the lattice parameters upon annealing. Philosophical Magazine, 2006, 87 (12), pp.1821-1844. 10.1080/14786430601083355 . hal-00513809

\section{HAL Id: hal-00513809 \\ https://hal.science/hal-00513809}

Submitted on 1 Sep 2010

HAL is a multi-disciplinary open access archive for the deposit and dissemination of scientific research documents, whether they are published or not. The documents may come from teaching and research institutions in France or abroad, or from public or private research centers.
L'archive ouverte pluridisciplinaire HAL, est destinée au dépôt et à la diffusion de documents scientifiques de niveau recherche, publiés ou non, émanant des établissements d'enseignement et de recherche français ou étrangers, des laboratoires publics ou privés. 


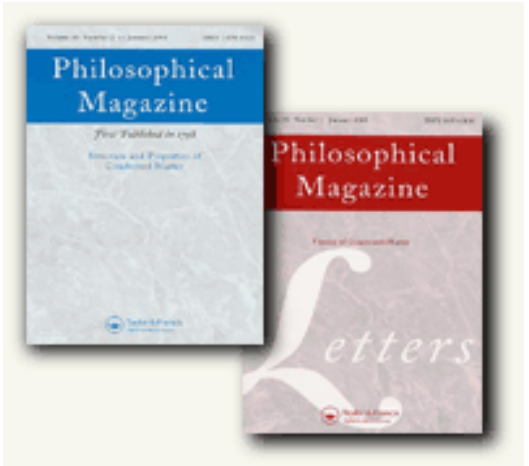

\section{Kinetics of ordering in $\mathrm{Ni}_{1.50} \mathrm{Sn}\left(\mathrm{Ni}_{3} \mathrm{Sn}_{2}\right.$ ') as revealed by the variation of the lattice parameters upon annealing}

\begin{tabular}{|r|l|}
\hline Journal: & Philosophical Magazine \& Philosophical Magazine Letters \\
\hline Manuscript ID: & TPHM-06-Jul-0268.R1 \\
\hline Journal Selection: & Philosophical Magazine \\
\hline Author: & 26-Sep-2006 \\
\hline & $\begin{array}{l}\text { Complete List of Authors: } \\
\text { Mittemeijer, Eric Jan; Max Planck Institute for Metals Research, } \\
\text { Knapp, Michael; Cells } \\
\text { Baehtz, Carsten; HASYLAB }\end{array}$ \\
\hline Keywords: & $\begin{array}{l}\text { kinetics, metallic alloys, phase transformations, phase transitions, } \\
\text { X-ray diffraction }\end{array}$ \\
\hline Keywords (user supplied): & order-disorder phenomena \\
\hline &
\end{tabular}

\section{S) ScholarONE \\ Manuscript Central}




\title{
Kinetics of ordering in $\mathrm{Ni}_{1.50} \mathrm{Sn}\left({ }^{(} \mathrm{Ni}_{3} \mathrm{Sn}_{2}{ }^{\prime}\right)$ as revealed by the variation
}

\section{of the lattice parameters upon annealing}

\author{
A. Leineweber ${ }^{1}$, E. J. Mittemeijer ${ }^{1}$, M. Knapp ${ }^{2}$, C. Baehtz ${ }^{3}$ \\ ${ }^{1}$ Max Planck Institute for Metals Research, Heisenbergstraße 3, 70569 Stuttgart, Germany \\ ${ }^{2}$ Institute for Materials Science, Darmstadt University of Technology, Petersenstraße 23, \\ 64287 Darmstadt, Germany \\ ${ }^{3}$ HASYLAB Hamburg, DESY, Notkestr. 85, 22607 Hamburg, Germany
}
A. Leineweber: a.leineweber@mf.mpg.de
E.J. Mittemeijer: e.j.mittemeijer@mf.mpg.de
M. Knapp: mknapp@cells.es
C. Baehtz: carsten.baehtz@desy.de 


\begin{abstract}
X-ray powder diffraction was employed to reveal the structural changes occurring upon annealing of quenched, hexagonal $\mathrm{Ni}_{1.50} \mathrm{Sn}$ below its equilibrium ordering temperature, leading finally to long-range ordered, orthorhombic $\mathrm{Ni}_{1.50} \mathrm{Sn}$. The changes in the diffraction patterns indicate that the features of the low-temperature phase develop gradually in two main stages. Ex-situ and in-situ time-resolved X-ray powder diffraction analysis of the first stage was employed to monitor at various temperatures in particular the time dependence of the lattice axial ratio $c / a$ associated with the formation of long-range order in small domains. Data evaluation using an 'equivalence-time' method gave a value of $165-170 \mathrm{~kJ} / \mathrm{mol}$ for the activation energy of the ordering, indicative of lattice-site changes of Ni atoms.
\end{abstract}

Keywords: kinetics, metallic alloys, phase transformations, phase transitions, X-ray diffraction, order-disorder phenomena 


\section{Introduction}

\subsection{Powder diffraction to measure phase transformation kinetics}

The kinetics of phase transformations in solids can be examined by various in-situ and ex-situ methods, e.g. thermal analysis, resistometry, dilatometry, quantitative optical and electron microscopy and diffraction methods. Ex-situ and in-situ time-resolved (powder) diffraction experiments provide direct information about both crystal structure changes and microstructure changes (as variation of domain size and (micro)strain) in the course of a transformation. Therefore, powder diffraction experiments in principle provide a wealth of structural data and are well suited to provide quantitative kinetic data, like activation energies and other characteristic parameters of the transformation-rate laws.

As compared to many other techniques, powder-diffraction experiments are timeconsuming and the collection of the diffraction data is often not sufficiently fast to trace the progress of a transformation in-situ. High-intensity synchrotron and neutron sources as well as the development of position-sensitive/energy-dispersive detector systems in the last 10-20 years led to a considerable increase of the number of reported in-situ powder diffraction studies $[1,2]$.

In order to extract kinetic information about a transformation from time-resolved powder-diffraction experiments specific, continuously changing characteristics of the diffraction patterns are determined (sometimes by incorporating a Rietveld refinement [3] applied to the entire diffraction pattern) as, in particular:

- Reflection intensities, which either are related with the amount of phase giving rise to the reflections considered (e.g. [4-6]) or, if superstructure reflections are considered, are a measure for the degree of order [7]. 
- Reflection positions, which can be used to determine the lattice parameters of a phase and thereby its composition, or to determine residual internal stress, fault density, etc.

- Reflection widths, which can be used to determine crystallite size (and thus allow tracing crystallite growth [8] or domain growth [9]) or microstrain.

Lattice-parameter changes are apparently less commonly used to monitor the kinetics of phase transformations, which may be due to the required accuracy of the measurements. For example, (ex-situ measured) lattice-parameter changes of supersaturated aluminiumsilicon [10] or aluminium-magnesium [11] solid solutions upon formation of precipitates were determined and interpreted in terms of composition change of the solid solution and the occurrence of hydrostatic macrostresses due to the precipitate / matrix (Al) misfit [12].

In the present paper continuous lattice-parameter changes occurring upon change in the state of order are measured and interpreted: Upon annealing an initially disordered hightemperature phase sample $\left(\mathrm{HT}-\mathrm{Ni}_{1.50} \mathrm{Sn}\right)$ below the equilibrium transformation temperature an ordered low-temperature superstructure phase $\left(\mathrm{LT}-\mathrm{Ni}_{1.50} \mathrm{Sn}\right)$ forms in a homogeneous fashion. This superstructure formation is accompanied by a continuous change of the lattice parameters. The lattice-parameter data are evaluated in order to determine kinetic parameters as the activation energy of ordering, without assuming a specific model for the transformation kinetics apart from adopting Arrhenius-type behaviour for the temperature dependence of the transformation kinetics with constant activation energy.

\subsection{Powder diffraction to measure phase transformation kinetics}

The different phases of the $\mathrm{Ni}_{1+\delta} \mathrm{Sn}$ field $(0.35 \leq \delta \leq 0.67$ [13]; often also referred to by the formula $\mathrm{Ni}_{3} \mathrm{Sn}_{2}$ ) in the phase diagram of the Ni-Sn system belong to the large group of $\mathrm{NiAs} / \mathrm{Ni}_{2}$ In type structures: $\mathrm{Ni}(1) \mathrm{Sn}$ forms an NiAs-type structure and $\mathrm{Ni}(2)$ atoms occupy, 


\section{Experimental}

\subsection{Alloy preparation; 'primary' heat treatment}

A HT-Ni $i_{1.50} \mathrm{Sn}$ bulk alloy [18] was prepared from appropriate amounts of $\mathrm{Ni}$ taken from sheets of $1 \mathrm{~mm}$ thickness (Goodfellow, 99.98 mass\%) and of Sn taken from bars (Heraeus 99.999 mass\%). The batch size was about $34 \mathrm{~g}$. The starting materials were melted by induction heating and cast into water-cooled cylindrical forms of $8 \mathrm{~mm}$ diameter and $50 \mathrm{~mm}$ length. The mass of the cast ingot confirmed that there was no significant loss of mass during melting and casting. The top and bottom parts of the cast cylinder were removed and the remaining material was sealed in an evacuated quartz tube and subjected to a homogenisation treatment of $3 \mathrm{~d}$ at $473 \mathrm{~K}$ to remove $\beta$-Sn-containing inhomogeneities in the cast alloy, avoiding their melting and subsequently $3 \mathrm{~d}$ at $1023 \mathrm{~K}$ followed by water quenching with crushing the quartz tube. 
About $2 \mathrm{~g}$ of the bulk alloy were ground in a mortar to form a powder with a particle size of 5-40 $\mu \mathrm{m}$. To relieve microstrains due to grinding, the powder was encapsulated within a quartz tube, and annealed at $1023 \mathrm{~K}$ for $15 \mathrm{~min}$ followed by water quenching without crushing the quartz tube. The $\mathrm{Ni}_{1.50} \mathrm{Sn}$ powder having experienced this heat treatment is further referred to as $\mathrm{HT}-\mathrm{Ni}_{1.50} \mathrm{Sn}$. Three different $\mathrm{HT}-\mathrm{Ni}_{1.50} \mathrm{Sn}$ powder batches (labelled HT1, HT2, HT3) were prepared and used in the following investigations (cf. Table 1).

Sodium chloride powder (used as internal standard for the in-situ powder diffraction experiments) was produced by grinding coarse-grained $\mathrm{NaCl}$ (Merck, pro analysi, >99.5 mass \%) in a mortar. The fine powder (particle size 2-30 $\mu \mathrm{m}$ ) was encapsulated in a quartz tube and annealed for $1 \mathrm{~h}$ at $773 \mathrm{~K}$ and cooled down by switching off the furnace. This heat treatment of the ground powder led to a significant decrease of the diffraction-line widths as compared to the as-ground state.

\subsection{Heat treatments of samples for ex-situ X-ray diffraction}

Samples of about 5-10 mg HT-Ni ${ }_{1.50} \mathrm{Sn}$ powder were encapsulated into quartz capillaries of an overall diameter of $2 \mathrm{~mm}$ and a wall thickness of $0.3-0.4 \mathrm{~mm}$. The heat treatments were performed in an oil bath thermostat (Julabo $5 \mathrm{HC}$ ) at $490 \mathrm{~K}(\mathrm{HT} 2), 510 \mathrm{~K}, 530 \mathrm{~K}$ and $550 \mathrm{~K}$ (HT1; used for evaluation of the kinetics by ex-situ experiments, section 2.4) or in a salt bath thermostat $(6050 \mathrm{H}$, Hart Scientific) at $553 \mathrm{~K}, 568 \mathrm{~K}$ (HT3; used for study of structural changes as described in section 2.3 ), or at $673 \mathrm{~K}$ in a resistivity furnace (HT1, to prepare 'well ordered' reference $\mathrm{LT}-\mathrm{Ni}_{1.50} \mathrm{Sn}$ by annealing for $5 \mathrm{~d}$ ). The capillaries were put into the hot fluid or furnace (this point in time was taken as $t_{\text {start }}$, the start of the annealing time period), and after the desired period of time (minimum $5 \mathrm{~min}$, maximum $70 \mathrm{~d}$ ), they were removed and quenched by putting the whole capillaries into water having ambient temperature. The 


\subsection{Ex-situ X-ray diffraction for structural characterisation of the HT $\rightarrow$ LT transformation}

In order to characterise the changes of the X-ray diffraction patterns occurring upon annealing of virginal $\mathrm{HT}-\mathrm{Ni}_{1.50} \mathrm{Sn}$ at $T \leq 673 \mathrm{~K}$, powder-diffraction data of various samples were collected at $300 \mathrm{~K}$ on a Philips X'Pert diffractometer equipped with a copper tube and an asymmetrically cut Ge single-crystal Johannson-type incident-beam monochromator selecting the K $\alpha 1$ component of the characteristic radiation. The sample powder was suspended in isopropanol and, by using a supporting brass ring, the liquid was poured onto a $\mathrm{Si}$ wafer cut along a (510) plane. The isopropanol was evaporated at the air leaving a thin, uniform layer of the $\mathrm{Ni}_{1.50} \mathrm{Sn}$ powder. From these samples diffraction patterns were recorded in the $2 \theta$ (diffraction angle) range of $24-47^{\circ}$. After the measurement, Ge powder ( $a=5.6574 \AA$ ) was additionally sedimented onto the sample, and a measurement in the $2 \theta$ range $25^{\circ}-68^{\circ}$ was performed for an accurate determination of the positions of the fundamental reflections of $\mathrm{Ni}_{1.50} \mathrm{Sn}$ as well as of the Ge standard reflections by subsequent fitting of symmetric pseudoVoigt functions [20]. The Ge standard reflections were used to calibrate the $2 \theta$ scale and to correct the positions of the fundamental reflections of $\mathrm{Ni}_{1.50} \mathrm{Sn}$ accordingly. These fundamental reflection positions were used to correct the $2 \theta$ scale of the above described initial measurements performed without Ge standard. These corrected diffraction patterns (see Figures 1 and 2) were used to identify the structural changes as discussed in section 3.1. Lattice parameters of $\mathrm{Ni}_{1.50} \mathrm{Sn}$ on the basis of these measurements are not presented here; all lattice parameters presented here originate either from Guinier diffraction experiments with internal Ge standard as described in section 2.4 or from diffraction experiments using synchrotron radiation with internal $\mathrm{NaCl}$ standard as described in section 2.5. 
Figure 1

Figure 2

\subsection{Ex-situ X-ray diffraction lattice-parameter determination}

The values of the lattice parameters of original (HT) and annealed $\mathrm{Ni}_{1.50} \mathrm{Sn}$ powders were determined from Guinier powder-diffraction patterns recorded at $296 \mathrm{~K}$ using an imagingplate camera (Huber G670) in transmission geometry and applying $\mathrm{Cu} \mathrm{K} \alpha 1$ radiation $(1.54056 \AA)$ and $\mathrm{Ge}$ as an internal standard $(a=5.6574 \AA)$. The $\mathrm{Ni}_{1.50} \mathrm{Sn}$ powders were mixed with the Ge powder, suspended together in isopropanol and sedimented onto the transmission powder holders (metal frame covered with Mylar foil; sedimentation procedure as described for substrate wafers in section 2.3). The sample was oscillated during data collection in order to improve crystal statistics.

The positions of the Ge reflections and of the fundamental reflections of $\mathrm{Ni}_{1.50} \mathrm{Sn}$ were determined using the programme CMPR [21] in the diffraction-angle range $26^{\circ} \leq 2 \theta \leq 67^{\circ}$ using pseudo-Voigt functions for all reflections. The diffraction-angle dependent instrumental peak-profile asymmetry was described simultaneously for the entire pattern [22] by fitting two additional fit parameters, according to which all the pseudo-Voigt profiles of all reflections are modified. The fundamental-reflection positions of $\mathrm{Ni}_{1.50} \mathrm{Sn}$ were corrected according to the reflection positions of the Ge standard reflections. Values for the lattice parameters (orthorhombic $a, b$, and $c$ for the reference $\mathrm{LT}-\mathrm{Ni}_{1.50} \mathrm{Sn}$ sample, hexagonal or pseudohexagonal (see section 3.1) $a$ and $c$ for all other samples) were refined from the corrected $\mathrm{Ni}_{1.50} \mathrm{Sn}$ fundamental reflection positions using the programme ASIN [23]. 


\subsection{In-situ X-ray diffraction for evaluation of transformation kinetics}

In-situ powder diffraction measurements were performed at the beamline B2 at HASYLAB employing monochromatic synchrotron radiation of a wavelength of $0.70952 \AA$ (as determined from the reflection positions of a powdery Si standard reference material). The powder patterns were recorded on a stationary imaging plate combined with an automated read-out system [24]. Quartz capillaries of $0.3 \mathrm{~mm}$ diameter were filled with a $60 \mathrm{wt} \%: 40$ wt $\%$ mixture of $\mathrm{HT}-\mathrm{Ni}_{1.50} \mathrm{Sn}$ and $\mathrm{NaCl}$ powder (cf. section 2.1) in an Ar-filled glove box, and, thereafter, the funnel of the capillary was sealed by molten wax. The capillaries were heated using a STOE capillary furnace flushed by a constant stream of nitrogen and controlled via a thermocouple close to the sample giving the nominal temperature. The actual sample temperature was determined on the basis of the measured $\mathrm{NaCl}$ lattice parameters (see section $3.2 .2)$

Diffraction patterns of sufficient quality for lattice-parameter determination could be obtained by exposures of $2 \mathrm{~min}$. Including the additional time needed for scanning and erasing of the image on the imaging plate, a measurement (covering a diffraction-angle range of 0 $90^{\circ} 2 \theta$ ) could be performed every 4 minutes. The reflections were symmetric and had a largely diffraction angle-independent full width at half maximum (FWHM) of $0.04^{\circ} 2 \theta$ (cf. Figure 3) due to instrumental resolution.

Figure 3 
The three high-temperature (Table 2) runs, using a 'virginal' sample for each run, were preceded by a measurement at ambient temperature (nominal temperature of about 294-295 $\mathrm{K})$. The sample was firstly heated up to a nominal temperature of $470 \mathrm{~K}$ where it stayed for two minutes to reach thermal equilibrium. Then, again within two minutes, the sample was heated up stepwise to the desired final nominal temperature $(533 \mathrm{~K}, 543 \mathrm{~K}, 558 \mathrm{~K}$; within a few seconds the nominal temperature reached the set-point temperature and there was virtually no 'overshoot' of the temperature). For the kinetic analyses the starting time for the annealing-time period, $t_{\text {start, }}$ was taken, when the final temperature was set.

At the three annealing temperatures a consecutive series of diffraction measurements with 2 min exposures was performed. The annealing time period $t-t_{\text {start }}$ associated with each diffraction measurement was defined as the time difference between the beginning of the concerned exposure, $t$, and the start of the annealing time period $t_{\text {start }}$ (see above). At the end of each high-temperature annealing run, the sample was cooled down to ambient temperature (nominal temperature of about 294-295 K) after which a final diffraction pattern was recorded.

All diffraction patterns collected in the course of the in-situ measurements were evaluated by extracting the reflection positions, of the $\mathrm{Ni}_{1.50} \mathrm{Sn}$ and $\mathrm{NaCl}$ reflections in the angular range of $12^{\circ}-38^{\circ}$, by fitting symmetric pseudo-Voigt functions to the reflections [21]. 11-13 $\mathrm{Ni}_{1.50} \mathrm{Sn}$ reflections (for some measurements the $\mathrm{Ni}_{1.50} \mathrm{Sn} 211$ and 004 reflections had to be excluded because upon annealing they increasingly overlap, and no reliable position values could then be determined for these reflections) and $7 \mathrm{NaCl}$ reflections had sufficient intensity to be fitted satisfactorily. 


\section{X-ray diffraction data: results and evaluation}

\subsection{Characterisation of the $H T \rightarrow L T$ transformation; two transformation stages}

The powder-diffraction patterns of HT- and LT-Ni ${ }_{1.50} \mathrm{Sn}\left(=\mathrm{HT}-\mathrm{Ni}_{1.50} \mathrm{Sn}\right.$ annealed for $5 \mathrm{~d}$ at $673 \mathrm{~K})$ are shown together in Figure 1. The corresponding lattice parameters have been listed in Table 1. Upon the HT to LT transformation the diffraction patterns reveal the following changes (Figures 2 (a) and (b) and see also $[18,25])$ :

(a) the development of superstructure reflections indicative of LT (from now on HT/LT are used in short for $\left.\mathrm{HT} / \mathrm{LT}-\mathrm{Ni}_{1.50} \mathrm{Sn}\right)$ and as consequence of the long-range ordering of $\mathrm{Ni}(2)$.

(b) changes in the lattice parameters, which are revealed by:

-splitting of the fundamental reflections (e.g. 110, but except 00l, eg. 002; see Fig. 1) exhibiting the orthorhombicity of the LT lattice. The so-called orthorhombic distortion, as compared to the hexagonal HT lattice, can be quantified by $2 b_{\mathrm{LT}} /\left(3^{1 / 2} a_{\mathrm{LT}}\right)-1$, being 0 for HT (in this case $b_{\mathrm{LT}}$ and $a_{\mathrm{LT}}$ should be identified with $3^{1 / 2} a_{\mathrm{HT}}$ and $2 a_{\mathrm{HT}}$; cf. section 1.2 ) and $>0$ for LT.

-expansion of the lattice along [001] upon transforming from HT to LT (note that the [001] direction is the same for both lattices in the chosen setting with Pbnm symmetry for LT), which is not reflected by the orthorhombic distortion defined above. This increase of the lattice parameter $c$ can be expressed by an effective $c / a$ axial ratio, $c_{\mathrm{LT}} /\left[a_{\mathrm{LT}} b_{\mathrm{LT}} /\left(2 \times 3^{1 / 2}\right)\right]^{1 / 2}=c_{\mathrm{LT}} / a_{\text {eff }} \quad\left(a_{\text {eff }}\right.$ is defined as the corresponding hexagonal lattice parameter $a$ giving the same unit area of the basal (001) plane, i.e. $\left.a_{\text {eff }}^{2}=(a / 2) \times\left(b / 3^{1 / 2}\right)\right)$, which is larger than the ratio $c_{\mathrm{HT}} / a_{\mathrm{HT}}$ for $\mathrm{HT}$.

Thus, the increase of long-range-order of $\mathrm{Ni}(2)$ upon going from HT to LT is associated with an increase of the (effective) axial ratio and of the orthorhombic distortion, in agreement with the general trends described in Ref. [18]. 
The long-range ordering of $\mathrm{Ni}(2)$ is virtually complete for samples equilibrated at $T \leq$ $673 \mathrm{~K}$ (see also introduction and Ref. [18]). Therefore, for the present annealing temperatures always the same fully ordered state is approached (asymptotically) as the equilibrium end point of the transformation.

Inspection of the diffraction data for intermediate states of the transformation shows that at least for $T \leq 580 \mathrm{~K}$ (comprising the main part of the investigated temperature range) the sequence of the different, successive changes in the powder-diffraction patterns (i.e. the 'path' towards equilibrium) is independent of the actual annealing temperature: the transformation mechanism appears constant; only the transformation rate changes (increases) with increasing temperature. Hence, for $\leq 580 \mathrm{~K}$ the transformation may be conceived as iso-kinetic [26, 27].

On the basis of the consecutive changes in the powder diffraction patterns the phase transformation HT $\rightarrow$ LT can roughly be subdivided into two main stages. The 1st stage of transformation is characterised by $2 \theta$-shifts of the fundamental (originally pure HT) reflections. These fundamental-peak shifts can be interpreted as an increase of the hexagonal lattice parameter $c$ and a decrease of the hexagonal lattice parameter $a$ (see the shifts of the reflections 002 and 110, Figure 2a), corresponding to an increase of the axial ratio $c / a$. Simultaneous to these lattice-parameter changes, very broad superstructure reflections become visible with increasing annealing time. After annealing for $1470 \mathrm{~min}$ at $553 \mathrm{~K}$, also some broadening of certain fundamental reflections occurs: Whereas the 002 reflection remains as narrow as for the original HT, other fundamental reflections broaden, as most strikingly shown by the $h k 0$ reflections (e.g. 110 ; see Figure $2 b$ ). This broadening anticipates the splitting of these reflections as required for the orthorhombic lattice parameters: 
$a_{\mathrm{LT}} / 2 \neq b_{\mathrm{LT}} / 3^{1 / 2}$, which means that the orthorhombic distortion $\neq 0$. This fundamental reflection broadening and splitting is denoted as the 2nd stage of transformation. Simultaneously, during the 2 nd stage, the superstructure reflections become narrower. At a progress of transformation beyond that produced by annealing for about $1440 \mathrm{~min}$ at $553 \mathrm{~K}$ (i.e. the 'earliest' stage of transformation allowing a reliable fitting of the superstructure reflections) the integrated intensities of the superstructure reflections are equal to those recorded for the reference LT sample. The powder diffraction patterns do not suggest that at any intermediate state of progress of transformation the two phases HT and LT are present simultaneously. Hence, the development of LT from HT appears not to occur by a processs of nucleation and growth of LT phase in a HT matrix, but to be realised by a gradual structural transition from all HT into LT.

These findings led to selection of annealing temperatures and time periods for the insitu and ex-situ experiments to investigate the kinetics of the 1st stage of ordering quantitatively from the time-dependence of the annealing-induced changes of the lattice parameters. Data for the kinetics of the 2nd stage will be presented elsewhere [28].

\subsection{Lattice-parameter changes upon annealing}

3.2.1 Ex-situ experiments The difference between the observed reflection positions and the reflection positions calculated from the refined lattice parameters, $\left|2 \theta_{\mathrm{obs}}-2 \theta_{\text {calc }}\right|$, was usually smaller than $0.005^{\circ}$. The resulting lattice-parameter data, plotted in a $c$ vs. $a$ fashion [29], are shown for the four annealing temperatures in Figure 4a. This plot indicates that the HT $\rightarrow$ LT 'path' through the ' $c-a$ space' is independent from the actual annealing temperature. Therefore, $a$ and $c$ individually or a combination of $a$ and $c$ as in the ratio $c / a$ can be used as a measurable parameter $p_{T_{0}}$, determined at a reference temperature $T_{0}=296 \mathrm{~K}$ (cf. section 2.4), 
to monitor the progress of the transformation (see appendix, in particular the 'Ex-situ isothermal annealing experiments' part). Here, $p_{T_{0}}$ is taken as $(c / a)_{0}$ (the index 0 indicates that the value pertains to $\left.T_{0}=296 \mathrm{~K}\right)$. The time-dependent evolution of the $(c / a)_{0}$ ratio for the (exsitu) annealed $\mathrm{Ni}_{1.50} \mathrm{Sn}$ is shown in Figure 5a for the various annealing temperatures; the $(c / a)_{0}$ value for the final, equilibrium LT phase, $(c / a)_{\text {eff }}$ (cf. Table 1), obtained by annealing at 673 $\mathrm{K}$, has also been indicated in Figure 5a.

\section{Table 1}

Figure 4

Figure 5

3.2.2 In-situ experiments, $2 \theta$ and temperature calibration The in-situ powder-diffraction data analysis requires calibration of both the $2 \theta$ scale and the specimen temperature. These calibrations were performed using the $\mathrm{HT}-\mathrm{Ni}_{1.50} \mathrm{Sn}$ and $\mathrm{NaCl}$ reflections, respectively, as follows. For each of the three high-temperature runs performed the lattice parameters of the $\mathrm{HT}-\mathrm{Ni}_{1.50} \mathrm{Sn}$ at the initial, ambient temperature (nominal temperature of 294-295 K), used for calibration of the $2 \theta$ scale, were taken equal to those obtained by the ex-situ diffraction experiments discussed in section 3.2.1 (measurements performed at $296 \mathrm{~K}$, Table 1). The lattice parameter of $\mathrm{NaCl}$, used temperature calibration, was taken as fit parameter.

By trial and error, two additive correction terms were found to provide a satisfactory correction of the $2 \theta$ scale for the corresponding ambient-temperature measurements (this correction was performed separately for each of the three high-temperature runs): (i) a constant $2 \theta$ shift of $\Delta 2 \theta=k_{1}$ and (ii) a $2 \theta$-dependent $2 \theta$ shift of $\Delta 2 \theta=k_{2} \cdot \cos ^{2} \theta / \sin \theta$, where $k_{1}$ 
and $k_{2}$ are fit parameters. Thus using all $\mathrm{HT}-\mathrm{Ni}_{1.50} \mathrm{Sn}$ and $\mathrm{NaCl}$ reflection positions obtained from an initial ambient temperature measurement the correction parameters $k_{1}$ and $k_{2}$ as well as the lattice parameter of $\mathrm{NaCl}$ were determined by fitting (taking $a$ and $c$ of $\mathrm{Ni}_{1.50} \mathrm{Sn}$ from Table 1 ; see above $)$ by minimising the sum of $\left(2 \theta_{\text {obs }}-2 \theta_{\text {calc }}\right)^{2}$ over all $\mathrm{Ni}_{1.50} \mathrm{Sn}$ and $\mathrm{NaCl}$ reflection positions in the considered angular range.

For the subsequent measurements at each annealing temperature (and also for the final measurement at ambient temperature) the $k_{2}$ value was held fixed. Only $k_{1}$ and the lattice parameters of the transforming $(\mathrm{HT} \rightarrow \mathrm{LT}) \mathrm{Ni}_{1.50} \mathrm{Sn}(a$ and $c)$ and of the reference $\mathrm{NaCl}(a)$ were fitted. The resulting differences between the observed and calculated (on the basis of the refined parameters) reflection positions, $\left|2 \theta_{\mathrm{obs}}-2 \theta_{\text {calc }}\right|$, were $\leq 0.002^{\circ}$ (usually $\leq 0.001^{\circ}$ ).

The actual specimen temperatures of the measurements conducted at ambient temperature (see section 2.5) and at the annealing temperatures were calculated from the corresponding refined values for the lattice parameter of $\mathrm{NaCl}$ by using a formula obtained by adopting the lattice parameter of the used $\mathrm{NaCl}$ batch as measured at $296 \mathrm{~K}(5.4307 \AA)$ and the thermal expansion data taken from Ref. [31]:

$$
a / \AA=5.6356+2.2393 \cdot 10^{-4}(T / \mathrm{K}-273.15)+7.692 \cdot 10^{-8}(T / \mathrm{K}-273.15)^{2}+2.281 \cdot 10^{-11}(T / \mathrm{K}-273.15)^{3} .
$$

For the initial measurements at ambient temperatures conducted on the virgin samples at nominal temperatures (as measured by the thermocouple of the furnace) of 294-295 K the determination of the actual sample temperature on the basis of the measured $\mathrm{NaCl}$ lattice parameter and application of Eq. (1) gave for all (three) runs 291-292 K, somewhat lower than the nominal temperatures (see Table 2). The difference between the nominal and actual ambient temperature is - due to the above procedure - somewhat overestimated, because the $296 \mathrm{~K}$ lattice parameters of $\mathrm{HT}-\mathrm{Ni}_{1.50} \mathrm{Sn}$ had been adopted to calibrate the $2 \theta$ scale. However, 
$\mathrm{NaCl}$ has a thermal expansion coefficient which is three times larger than that of $\mathrm{Ni}_{1.50} \mathrm{Sn}$ (as estimated from the present data). Therefore, for the measurements at the annealing temperatures this error is negligible.

The obtained $\mathrm{NaCl}$ lattice-parameter values for the measurements at the three annealing temperatures show a largely annealing-time independent scatter of $\pm 0.0002 / 3 \AA$ (see Table 2; systematic temperature deviation occurring at the very early stage of annealing is discussed below), corresponding to $\pm 1 \mathrm{~K}$ for each of the actual (average) annealing temperatures (Eq. (1)). The actual annealing temperatures of the high temperature runs $(516 \mathrm{~K}, 527 \mathrm{~K}$ and 541 $\mathrm{K})$ were $16-17 \mathrm{~K}$ lower than the nominal temperatures $(533 \mathrm{~K}, 543 \mathrm{~K}$ and $558 \mathrm{~K}$; see Table 2). This difference between actual and nominal temperature is consistent with measurements from a thermocouple replacing the sample capillary [32].

At the lowest and highest annealing temperatures the exposure of the first diffraction measurement started one minute after setting the nominal temperature. The $\mathrm{NaCl}$ lattice parameters of these measurements, after one minute, were significantly lower than those of the following measurements say, after 6-10 min. This indicates that during the first few minutes the actual sample temperature had not reached its stationary value, which is, however, neglected in the further data analysis..

Plotting $c$ vs. $a$ for the high-temperature in-situ measurements (Figure 4b) leads to three different evolutions with increasing progress of transformation for the three different annealing temperatures, whereas the results of the ex-situ experiments (recorded at $296 \mathrm{~K}$ ) for the different annealing temperatures in such a plot coincide (Fig. 4a vs. Fig. 4b). This obviously reflects the effect of the different thermal expansions experienced at the different annealing temperatures. This thermal expansion is superimposed on the lattice-parameter 
change occurring due to the phase transformation. It is expected that the axial ratio $c / a$ is much less sensitive for thermal expansion than the individual lattice parameters (if the thermal expansion is not too anisotropic, which is not the case here; see below). For the limited range of annealing temperatures in this study, $516 \mathrm{~K}<T<541 \mathrm{~K}$, it is fully justified for each stage of transformation to take the ratio $c / a(T)$ as independent of temperature, and thus the asmeasured ratio $(c / a)_{\mathfrak{T}}$ (the index $\mathfrak{T}$ indicates that $c / a$ was calculated from $a$ and $c$ measured at a temperature from the limited range of annealing temperatures) then can be taken as a suitable measure $p_{\mathfrak{z}}$ to trace the progress of transformation for the in-situ experiments (cf. 'Insitu isothermal annealing experiments' part of the Appendix). The $(c / a)_{\mathfrak{z}}$ ratios as calculated from the in-situ measured lattice parameters of $\mathrm{Ni}_{1.50} \mathrm{Sn}$ have been plotted vs. the annealing time in Figure 5b.

Over a large temperature range, however, the ratio $c / a(T)$ cannot be taken as constant for a specific stage of transformation: e.g. for well-ordered LT-Ni $1_{1.50} \mathrm{Sn}$ (measurements performed under equilibrium conditions) $(c / a)_{\text {eff }}$ increases substantially from 1.269 at $300 \mathrm{~K}$ to 1.270 at $650 \mathrm{~K}$ [30], i.e. by about $1 / 3$ of the change of $(c / a)_{\mathfrak{\tau}}$ covered by in the in-situ experiments (see also section 5.1). 


\section{Transformation kinetics}

\subsection{Analysis of the ex-situ data}

Having chosen the axial ratio $(c / a)_{0}$ calculated from the lattice parameters measured at $296 \mathrm{~K}$ (as indicated by the index 0) as the parameter $p_{T_{0}}$ tracing the progress of transformation, the kinetic analysis can be performed on the basis of Eq. (A7) provided that the activation energy $Q$ is constant for the part of the transformation covered by the values of $p_{T_{0}}$ (i.e. the 1 st stage of the transformation) and taking $t_{\text {start }}$ as the time at which the samples were put into the oil bath at the annealing temperature. Plots of $p_{T_{0}}=(c / a)_{0}$ vs. $\ln \left(t-t_{\text {start }}\right)$ are shown in Figure 6a. Indeed, as predicted by Eq. (A7), isomorphous curves occur, shifted with respect to each other along the abscissa $\left(\ln \left(t-t_{\text {start }}\right)\right.$ axis $)$ due to the differences in annealing temperature.

A fraction transformed scale, $f_{(c / a)_{0}}$, can be be obtained from (see also Eq. (A1))

$f_{(c / a)_{0}} \equiv \frac{p_{T_{0}}-p_{T_{0}, \text { start }}}{p_{T_{0}, \text { end }}-p_{T_{0}, \text { start }}}=\frac{(c / a)_{0}-(c / a)_{0, \mathrm{HT}}}{(c / a)_{0, \mathrm{LT}}-(c / a)_{0, \mathrm{HT}}}$

where $p_{T_{0}, \text { start }}=(c / a)_{0, \mathrm{HT}}=1.2625(c / a$ value of the HT2 batch, cf. Table 1$)$ and $p_{T_{0} \text {,end }}=$ $(c / a)_{0, \mathrm{LT}}=1.2687$ (effective $c / a$ for LT phase sample, $\mathrm{cf}$. Table 1) were applied for all data. This leads to the second ordinate axis in Figure 6a, implying also data evaluation according to Eq. (A6a).

The activation energy $Q$ is obtained by determining the distances by which the 'isomorphous' $f_{p_{T_{0}}}=f_{(c / a)_{0}}$ (or $\left.p_{T_{0}}=(c / a)_{0}\right)$ vs. $\ln \left(t-t_{\text {start }}\right)$ curves of the different annealing temperatures are shifted with respect to each other along the abscissa. For that purpose these curves are described using polynomials according to (compare Appendix, Eq. (A6a) (or Eq. (A7)) either 


$$
\ln \left(t-t_{\text {start }}\right)=A_{3} f_{(c / a)_{0}}^{3}+A_{2} f_{(c / a)_{0}}^{2}+A_{1} f_{(c / a)_{0}}+A_{0, T}=\ln \tau\left(f_{(c / a)_{0}}\right)+Q / R T
$$

or alternatively according to

$$
\ln \left(t-t_{\text {start }}\right)=B_{3}(c / a)_{0}^{3}+B_{2}(c / a)_{0}^{2}+B_{1}(c / a)_{0}+B_{0, T}=\ln \tau\left((c / a)_{0}\right)+Q / R T
$$

with common, annealing-temperature independent, fitted coefficients $A_{n}\left(B_{n}\right)$ for $n>0$ and temperature dependent fitted coefficients $A_{0, T}$ (or $\left.B_{0, T}\right) . \tau\left(f_{(c / a)_{0}}\right)$ (or $\tau\left((c / a)_{0}\right)$ ) is the time needed (hypothetically) at $T=\infty$ for the system to transform from the starting value of $f_{(c / a)_{0}}$ $=0$ (or $\left.p_{T_{0} \text {,start }}=(c / a)_{0, \mathrm{HT}}\right)$, corresponding to the initial HT phase, to a value of $f_{(c / a)_{0}}$ (or $\left.(c / a)_{0}\right)$

Fitting of $A_{n}$ and $B_{n}$ was performed for $0.125 \leq f_{(c / a)_{0}} \leq 0.865$ or correspondingly for $1.2633 \leq(c / a)_{0} \leq 1.2678$, i.e. for the ranges for which data were available for all annealing temperatures. Numerically, convergence was easier achieved for the fraction transformed $f_{(c / a)_{0}}$ scale than for the parameter $p_{T_{0}}=(c / a)_{0}$ scale. Note that a polynomial as given by the middle part of Eq. (3) must fail close to $f_{(c / a)_{0}}=0$ and $f_{(c / a)_{0}}=1$ at which $\ln \left(t-t_{\text {start }}\right)$ would have to approach $-\infty\left(' \ln (0)^{\prime}\right)$ and $+\infty\left(' \ln (\infty)^{\prime}\right)$, respectively.

According to Eq. (3) an Arrhenius-type plot of $A_{0, T}$ vs. 1/T (cf. Figure 7a) exhibits a slope of $+Q / R$ and an intercept of the ordinate equal to $A_{0}$ as given by the equation $A_{0, T}=A_{0}+$ $Q / R T$. As a result for the ex-situ data an activation energy of $Q=164(4) \mathrm{kJ} / \mathrm{mol}$ has been obtained (Figure 7a), with the indicated standard deviation due to the scatter of the $A_{0, T}$ values as determined for the three different annealing temperatures.

Figure 6 


\section{Figure 7}

\subsection{Analysis of the in-situ data}

As discussed in section 3.2.2, for the limited range of annealing temperatures considered, 516 $\mathrm{K} \leq T \leq 541 \mathrm{~K}$, the axial ratio $(c / a)_{\mathfrak{T}}$ as determined from the lattice parameters at the annealing temperatures within this range, is a characteristic measure for the progress of transformation and takes the role of $p_{\mathfrak{T}}$ (see 'In-situ isothermal annealing experiments' part of the appendix $)$. Indeed, a plot of $(c / a)_{\mathfrak{T}}$ vs. $\ln \left(t-t_{\text {start }}\right)$ gives 'isomorphous' curves shifted along the $\ln \left(t-t_{\text {start }}\right)$ axis due to the different annealing temperatures (Figure $5 \mathrm{~b}$; cf. discussion in section 4.1).

Calculation of fraction-transformed values from $p_{\mathfrak{T}}=(c / a)_{\mathfrak{T}}$ can in principle be performed according to

$$
f_{(c / a)_{\mathrm{T}}}=\frac{p_{\mathrm{T}}-p_{\mathrm{T}, \text { start }}}{p_{\mathrm{T}, \text { start }}-p_{\mathrm{T}, \text { end }}}=\frac{(c / a)_{\mathrm{T}}-(c / a)_{\mathrm{T}, \mathrm{HT}}}{(c / a)_{\mathrm{T}, \mathrm{LT}}-(c / a)_{\mathrm{T}, \mathrm{HT}}} .
$$

where $(c / a)_{\mathfrak{T}, \mathrm{HT}}$ and $(c / a)_{\mathfrak{T}, \mathrm{LT}}$ correspond to the (effective) axial ratios pertaining to the start HT state and the end LT state. The values for $(c / a)_{\mathfrak{T}, \mathrm{HT}}$ and $(c / a)_{\mathfrak{T}, \mathrm{LT}}$ can be assumed to be constant within the limited annealing-temperature range due to the sufficiently isotropic thermal expansion in that temperature range (see end of section 3.2.2; see also 'In-situ isothermal annealing experiments' part of the appendix).

Whereas $(c / a)_{\mathfrak{T}, \mathrm{LT}}$ can be obtained from in-situ diffraction data of equilibrium LT$\mathrm{Ni}_{1.50} \mathrm{Sn}$ like those given in Figure $4 \mathrm{~b}$, it is extremely difficult to experimentally determine 
reliable data for $(c / a)_{\mathfrak{T}, \mathrm{HT}}$ because this state is highly unstable at the applied annealing temperatures. Therefore, instead of making estimates for $(c / a)_{\mathfrak{T}, \mathrm{HT}}$, an auxiliary $\tilde{f}_{(c / a)_{\top}}$ scale has been employed:

$$
\tilde{f}_{(c / a)_{\mathrm{T}}} \equiv \frac{p_{\mathrm{T}}-p_{T_{0}, \text { start }}}{p_{T_{0}, \text { end }}-p_{T_{0}, \text { start }}}=\frac{(c / a)_{\mathrm{T}}-(c / a)_{0, \mathrm{HT}}}{(c / a)_{0, \mathrm{LT}}-(c / a)_{0, \mathrm{HT}}}
$$

where the values $p_{T_{0} \text {,start }}$ and $p_{T_{0} \text {,end }}$ are the same as those used for the ex-situ data.

For determination of the activation energy a polynomial description in $\tilde{f}_{(c / a)_{\top}}$ analogous to Eq. (3) can be applied:

$$
\ln \left(t-t_{\text {start }}\right)=\tilde{A}_{3} \cdot \tilde{f}_{(c / a)_{\top}}^{3}+\tilde{A}_{2} \cdot \tilde{f}_{(c / a)_{\top}}^{2}+\tilde{A}_{1} \cdot \tilde{f}_{(c / a)_{\top}}+\tilde{A}_{0, T}=\ln \tilde{\tau}\left(\tilde{f}_{(c / a)_{\top}}\right)+Q / R T
$$

For fitting of $\tilde{A}_{n}$ to the experimental data points the range $0.31 \leq \tilde{f}_{(c / a)_{\top}} \leq 0.75$ was applied, for which data from all three annealing temperatures were available. An Arrhenius-type plot of $\tilde{A}_{0, T}$ vs. $1 / T$ (cf. Figure $7 \mathrm{~b}$ ) provides a value for the activation energy $Q$ of the transformation. It was obtained: $169(9) \mathrm{kJ} / \mathrm{mol}$ with a standard deviation determined as for the ex-situ data. Hence, the activation-energy values derived from the ex-situ experiments and the in-situ experiments are the same within experimental accuracy.

\section{Discussion}

\subsection{Comparison of the transformation kinetcis of the ex-situ and the in-situ data}

The correctness of the assessment of the annealing temperature for the in-situ experiments can be checked as follows. The $(c / a)_{0}$ value (and the $f_{(c / a)_{0}}$ value calculated according to Eq. (2)) of the final measurements at ambient temperature for the in-situ experiments (Table 2) can be compared with the results from the ex-situ experiments: From the $f_{(c / a)_{0}}$ value and the total 
annealing time pertaining to the in-situ run considered, a value for the annealing temperature applied can be calculated adopting Eq. (3) (with $A_{0}, \ldots A_{3}$ and $Q$ as determined on the basis of the analysis of the ex-situ data). The thus independently obtained values for the annealing temperatures (Table 2) of the in-situ annealing experiments agree well with the temperatures derived from the value of the reference $\mathrm{NaCl}$ lattice parameter.

The thus demonstrated consistency of the annealing temperatures as used in the ex-situ experiments and as determined from the reference $\mathrm{NaCl}$ lattice parameter for the in-situ experiments, allows direct comparison of the derived transformation kinetics, as given by Eq. (4) and Eq. (7): here), because the $\ln \left(t-t_{\text {start }}\right)$ terms of both equations can be taken equal, i.e.

$$
A_{3} f_{(c / a)_{0}}^{3}+A_{2} f_{(c / a)_{0}}^{2}+A_{1} f_{(c / a)_{0}}+A_{0}+Q^{0} / R T=\tilde{A}_{3} \tilde{f}_{(c / a)_{\top}}^{3}+\tilde{A}_{2} \tilde{f}_{(c / a)_{\top}}^{2}+\tilde{A}_{1} \tilde{f}_{(c / a)_{\top}}+\tilde{A}_{0}+Q^{\top} / R T
$$

where the upper indices 0 and $\mathfrak{T}$ are introduced for the activation energy to allow distinction between the (virtually identical) activation energies determined from the ex-situ and in-situ data. Adopting this identity, and trying to relate the two fraction transformed parameters, one can propose to express $\tilde{f}_{(c / a)_{\mathrm{T}}}$ by a polynomial in $f_{(c / a)_{0}}$, $\tilde{f}_{(c / a)_{\top}}\left(f_{(c / a)_{0}}\right)=C_{3} f_{(c / a)_{0}}^{3}+C_{2} f_{(c / a)_{0}}^{2}+C_{1} f_{(c / a)_{0}}+C_{0}$

Then, after substitution of $\tilde{f}_{(c / a)_{\top}}$ according to Eq. (9) in the right-hand side of Eq. (8), the values for $C_{0}, \ldots C_{3}$ can in principle be determined by fitting. \{footnote: Although $Q^{0}$ and $Q^{\mathfrak{T}}$ are virtually equal, one cannot simply determine $C_{0}, \ldots C_{3}$ after deletion of $Q / R T$ at both sides of Eq. (8). This is due to the correlations between $Q^{0}$ and $A_{0}$, and $Q^{\mathfrak{T}}$ and $\tilde{A}_{0}$. Therefore, the evaluation is done for a specific temperature located within the annealing temperature ranges for the ex-situ and in-situ data. $\}$ To this end, $T=527 \mathrm{~K}$ was chosen here to fit $C_{0}, \ldots C_{3}$ by minimising the sum of the squared differences between both sides of Eq. (8) for certain $f_{(c / a)_{0}}$ 
ranges. It was found that already excellent agreement between the two sides of Eq. (8) is obtained by fixing $C_{3}=C_{2}=0$ and only fitting $C_{1}$ and $C_{0}$. As a result, fitting over fractiontransformed ranges for which data of both ex-situ and in-situ experiments were available (corresponding to $0.31 \leq \tilde{f}_{(c / a)_{\top}} \leq 0.75$; see section 4.2), it was obtained

$\tilde{f}_{(c / a)_{\top}}=1.01 f_{(c / a)_{0}}+0.16$

which describes the relation between the fraction transformed values $f_{(c / a)_{0}}$ and $\tilde{f}_{(c / a)_{\top}}$ at a given progress of transformation.

Eq. (10) can now be used to derive via Eq. (2) and Eq. (6) the relation between $(c / a)_{0}$ at ambient temperature and $(c / a)_{\mathfrak{\tau}}$ measured at the annealing temperatures for the same progress of transformation for the range $0.31 \leq \tilde{f}_{(c / a)_{\top}} \leq 0.75$ covered by the experiments. It is obtained $(c / a)_{\mathfrak{T}}=1.01(c / a)_{0}-0.0114$

Application of this linear relation between $(c / a)_{0}$ and $(c / a)_{\mathfrak{T}}$ to the whole range of the transformation, it finally follows from Eq. (2) and (5):

$f_{(c / a)_{\mathrm{T}}}=f_{(c / a)_{0}}$,

which holds for the same progress of transformation (see also discussion above Eq. (A2) in the appendix), i.e. the fraction-transformed scales $f_{(c / a)_{\top}}$ and $f_{(c / a)_{0}}$ are equal. Eq. (11) also allows to calculate $(c / a)_{\mathfrak{T}, \mathrm{HT}}$ and $(c / a)_{\mathfrak{T}, \mathrm{LT}}$ from $(c / a)_{0, \mathrm{HT}}=1.2625$ and $(c / a)_{0, \mathrm{LT}}=1.2687$ (cf. Table 1), yielding $(c / a)_{\mathfrak{T}, \mathrm{HT}}=1.2635$ and $(c / a)_{\mathfrak{T}, \mathrm{LT}}=1.2697$. These values could then be used to calculate $f_{(c / a)_{\top}}$ directly from $(c / a)_{\mathfrak{T}}$ according to Eq. (5), which is included in Figure 6b. The value obtained for $(c / a)_{\mathfrak{T}, \mathrm{LT}}=1.2697$ indeed agrees well with the value of 1.2701 for the 
$(c / a)_{\text {eff }}$ of $\mathrm{LT}-\mathrm{Ni}_{1.50} \mathrm{Sn}$ as measured under equilibrium conditions in that temperature range (see Figure 3b) [30].

\subsection{The mechanism of ordering in $\mathrm{Ni}_{1.50} \mathrm{Sn}$}

A simultaneous presence of the LT and the HT phases does not occur according to the X-ray diffraction data (section 3.1). Hence the development of LT does not occur by nucleation and growth of LT in a matrix of and at the cost of the initial HT. Instead, the 1st stage of transformation involves the gradual formation of long-range ordered LT, e.g. by so-called spinodal ordering [33]: In a phase exhibiting an order-disorder phase transition which is of 1st order character at the equilibrium transition temperature $T_{\mathrm{t}}$ (roughly $790 \mathrm{~K}$ for LT $\rightarrow$ HT $\mathrm{Ni}_{1.50} \mathrm{Sn}$ ) ordering at (close to) $T_{\mathrm{t}}$ has to occur by nucleation and growth, because infinitesimal fluctuations of the degree of long-range order away from zero pertaining to the HT phase, lead to an increase in Gibbs energy of the system. This situation can be different below a temperature called [33] $T_{i}^{-}$with $T_{i}^{-}<T_{\mathrm{t}}$, where similarly small fluctuations of the degree of order already lead to a decrease of the Gibbs energy of the system. Then nucleation is not required, and the degree of order can increase homogeneously, i.e. everywhere in the system.

At the end of the 1st stage the ordering is complete with respect to the magnitude of the order parameter, because the superstructure reflections have attained their final integral intensities (section 3.1). However, the large width of the superstructure reflections indicates a small size of the ordered regions. This can be understood by domain formation: In the course of an ordering phase transformation, an originally disordered crystal will usually not transform into a one single ordered crystal, but it will split up into many small ordered domains separated by anti-phase boundaries and/or by (transformation-)twin boundaries, depending on the group-subgroup relationship of the ordered and disordered phases [34]. In 
the present case, both rotations and translations are lost as symmetry elements upon the symmetry reduction from $P 6_{3} / m m c$ (HT) to Pbnm (LT). Consequently, both anti-phase and twin-boundaries separate the ordered LT domains. Such a LT state consisting of small domains is the starting point of the following 2 nd stage of transformation, which is characterised by coarsening of the ordered domains, which is typical for a disorder $\rightarrow$ order transition if initially small domains are formed [35].

It must be pointed out that as soon as the superstructure reflections become visible, $\mathrm{Ni}_{1.50} \mathrm{Sn}$ must be regarded as orthorhombic, although the fundamental reflections are still unsplit, i.e. the orthorhombic distortion $=0$ (section 3.1). In that 'pseudohexagonal' state it holds $a_{\mathrm{LT}} / 2=b_{\mathrm{LT}} / 3^{1 / 2}$, implying that the LT domains are highly strained with respect to the ideal LT structure. The diffraction-line broadening of the fundamental reflections at the transition of the $1 s t$ to the $2 n d$ stage and the finally observed splitting of the fundamental reflections indicate that the local strains reduce as the domains become larger until the lattice parameters of the LT assume their ideal values.

The rate-determining step for the ordering process during the 1 st stage of the transformation is likely site changes of $\mathrm{Ni}(2)$ atoms. The site-change process was described in an earlier work [36] for $\mathrm{Ni}_{1.56} \mathrm{Sn} / \mathrm{Ni}_{1.63} \mathrm{Sn}$ on the basis of data on the anisotropy of the temperature-dependent tracer diffusion coefficient for $\mathrm{Ni}$ as follows: first, a $\mathrm{Ni}(1)$ atom jumps to a vacant $\mathrm{Ni}(2)$ site; then the generated vacancy on the $\mathrm{Ni}(1)$ site is refilled by an(other) $\mathrm{Ni}(2)$ atom from its surroundings. However, the temperature dependence of the tracerdiffusion coefficient of $\mathrm{Ni}$ in HT yielded an activation energy of $206 \mathrm{~kJ} / \mathrm{mol}$ [36], which is much higher than the value found here for the activation energy of the ordering (1st stage) which equals $165-170 \mathrm{~kJ} / \mathrm{mol}$ (section 4). The presently found value for the activation energy of the 1 st stage determined by isothermal X-ray diffraction methods agrees well with values 
determined by isochronal DSC measurements, evaluated by a Kissinger-like method [27] for reordering of $\mathrm{HT}-\mathrm{Ni}_{1.50} \mathrm{Sn}$ which had been produced by ball milling of $\mathrm{LT}-\mathrm{Ni}_{1.50} \mathrm{Sn}$ [37]. Similar DSC experiments were performed by the present authors on $\mathrm{HT}-\mathrm{Ni}_{1.50} \mathrm{Sn}$ obtained by quenching; the value found for the activation energy agreed well with the value for the activation energy determined here on the basis of powder diffraction data.

The difference between the activation energy determined for tracer diffusion of $\mathrm{Ni}$ in HT [36] and the presently found values for the activation energy of ordering may be related to the considerably different temperatures at which the different experiments have been carried out: $870 \mathrm{~K}-1470 \mathrm{~K}$ in case of Ref. [36] and below $550 \mathrm{~K}$ in the present work (below $650 \mathrm{~K}$ in case of Ref. [37]). Due to the order-disorder phenomena of Ni(2) different local environments for site-changing $\mathrm{Ni}(2)$ atoms can occur in a crystal, so that the different individual activationenergy barriers for the required site changes may differ; a spectrum of activation energies may occur. This leads to the expectation that the effective activation-energy barrier for site changes of $\mathrm{Ni}(2)$ may be higher at higher temperatures when 'more difficult' jumps also contribute to the site changes. Moreover, the experiments presented in Ref. [36] were conducted on $\mathrm{Ni}_{1+\delta} \mathrm{Sn}$ with $\delta=0.56$ and 0.63 , i.e. higher than $\delta=0.50$ as employed in this study and one cannot exclude a concentration-dependence of the activation energy: a higher Ni content of the alloys, as in Ref. [36], leads to a higher fraction of trigonal-bipyramidal sites occupied by $\mathrm{Ni}(2)$ and thus a smaller fraction of empty ones. A decrease of the fraction of vacant trigonalbipyramidal sites may cause an increase of the activation-energy barrier of $\mathrm{Ni}(2)$ jumps due to a denser (in terms of the number of atoms) environment around the site-changing $\mathrm{Ni}(2)$ atom, because this denser environment may obstruct atomic displacements associated with the $\mathrm{Ni}(2)$ site-change processes.

\section{Conclusions}


(a) The structural changes induced upon annealing of quenched hexagonal $\mathrm{HT}-\mathrm{Ni}_{1.50} \mathrm{Sn}$ below its equilibrium order-disorder transition temperature, leading finally to fully long-range ordered, orthorhombic LT-Ni ${ }_{1.50} \mathrm{Sn}$, occur continuously and homogeneously. Two main stages of the transformation can be identified:

1st stage: Establishment of long-range order in small domains, leading to broad superstructure reflections, accompanied by continuous lattice-parameter changes of the still apparently hexagonal lattice, as expressed by an increase of the axial ratio $c / a$.

2nd stage: Coarsening of the initially small ordered domains leading to a narrowing of the superstructure reflections, accompanied first by a broadening and then by a splitting of fundamental, originally HT reflections thus exhibiting the orthorhombicity of the LT phase superstructure. The coarsening is also accompanied with a significant strain reduction in the ordered domain microstructure.

(b) Analysis of ex-situ and in-situ time-resolved X-ray powder diffraction data obtained on the 1st stage of the transformation (establishment of long-range ordering) allows full and consistent description of the ordering kinetics. The value determined for the activation energy of the ordering, as derived from isothermal experiments applying the equivalence time method equals $165-170 \mathrm{~kJ} / \mathrm{mol}$. This activation energy is most probably associated with the mobility of the Ni atoms required for establishment of long-range order. 


\section{Appendix: The equivalence-time method for analysis of isothermal transformation}

\section{kinetics}

In this appendix the basic equations are derived which have been used in this work for the evaluation of the ordering kinetics in $\mathrm{Ni}_{1.50} \mathrm{Sn}$ applying the equivalence-time method to isothermally conducted experiments $[26,27]$. Consider a thermally activated transformation spontaneously occurring upon annealing of a solid at a temperature $T$ within a certain temperature window, $T_{\min }<T<T_{\max }$. In this temperature range the transformation mechanism is assumed to be nonvariant ('isokinetics' prevails), i.e. the transformation proceeds 'in the same way', also involving that start and end stages of the process are the same, for each of the annealing temperatures within the considered range.

The progress of such a transformation can be traced by measuring a quantity $p$ which is assumed to change monotonously with the degree of the transformation (the term progress of transformation is taken as an abstract measure for the progress of the process).

Often it is convenient to project the quantity $p$ on a fraction transformed scale $f_{p}$ (fraction transformed is used here as a quantitative measure for the progress of transformation which assumes the values 0 and 1 at the begin and at the start of the transformation, respectively) according to

$f_{p}(p) \equiv \frac{p-p_{\text {start }}}{p_{\text {end }}-p_{\text {start }}}$

where $p_{\text {start }}$ and $p_{\text {end }}$ correspond to the values of $p$ at the start and at the end of the transformation. The index $p$ of the fraction $f_{p}$ indicates that the parameter $p$ has been used for calculation of the fraction transformed. The subscript can be useful because application of Eq. (A1) to another measurable parameter, say $q$ (for which $q_{\text {start }}$ and $q_{\text {end }}$ are known), only gives 
equal fraction transformed scales, $f_{q}=f_{p}$, if $\partial p / \partial q=$ const., i.e. $p$ and $q$ then must be linearly related:

$q=\mu+\gamma p$

This relation may be satisfied in many practical cases, but, in principle, each possible measurable variable may give rise to its own fraction-transformed scale and then for the same progress of transformation $f_{q} \neq f_{p}$ holds.

In any case, a reaction 'velocity' $v_{p}$ at a certain value of $f_{p}$ can be defined as

$$
v\left(f_{p}\right)=\frac{d f_{p}}{d t}
$$

which is assumed to exhibit an Arrhenius-type temperature dependence at each value of $f_{p}$ :

$$
v_{p}\left(f_{p}\right)=\left.\frac{d f_{p}}{d t}\left(f_{p}\right)\right|_{T=\infty} \exp \left(-Q\left(f_{p}\right) / R T\right)=v_{0}(f) \exp \left(-Q\left(f_{p}\right) / R T\right)
$$

with $v_{0}(f)$ as the temperature-independent pre-exponential factor. Note that 'isokinetics' does not require that $Q$ is independent of $f_{p}$ [38]. If the activation energy is constant over the transformation, i.e. $Q\left(f_{p}\right)$ is independent of $f_{p}$, the differential equation (A4) may be solved by integration from a starting time $t_{\text {start }}$, at which $f_{p}=0$ holds, to a time $t$ at which $f_{p}$ is measured, leading to

$$
\int_{0}^{f} \frac{d f_{p}^{\prime}}{v_{0}\left(f_{p}^{\prime}\right)}=\tau\left(f_{p}\right)=\exp (-Q / R T)\left(t-t_{\text {start }}\right)
$$

where the integral takes the same value $\tau(f)$ at each $T$. After taking the logarithm at both sides of Eq. (A5) it follows:

$$
\ln \tau\left(f_{p}\right)+Q / R T=\ln \left(t-t_{\text {start }}\right) .
$$

or, if the reaction does not start at $f_{p}=0$ but at $f_{p}=f_{p}^{*}$ at the time $t_{\text {start }}^{*}$, one obtains

$$
\ln \left[\tau\left(f_{p}\right)-\tau\left(f_{p}^{*}\right)\right]+Q / R T=\ln \left(t-t_{\text {start }}^{*}\right)
$$


It follows that $\tau\left(f_{p}\right)\left(\tau\left(f_{p}\right)-\tau\left(f_{p}^{*}\right)\right)$ can be interpreted as the time period needed to reach the value $f$ starting from $f_{p}=0\left(f_{p}=f_{p}^{*}\right)$ at $T=\infty$.

Eqs. (A6a) and (A6b) are the basic kinetic equations for the so-called equivalence-time method: If one knows the annealing-time period needed to carry out the transformation from a start value $f_{p}=0$ (Eq. (A6a) or $f_{p}=f_{p}^{*}$ (Eq. (A4b) to a certain end value, e.g. $f_{p}^{* *}$, at various annealing temperatures $T$, an Arrhenius type plot of $\ln \left(t-t_{\text {start }}\right)$ vs. $1 / T$ yields a straight line with a slope of $+Q / R$.

This method can be generalised if for various annealing temperatures the evolution of (a suitable parameter $p$ and thus) the fraction transformed $f_{p}$ has been measured as function of the annealing-time period $t-t_{\text {start }}$. In that case the analysis of a plot of $f_{p}$ vs. $\ln \left(t-t_{\text {start }}\right)$ can be employed for data evaluation, which can explained as follows. For each value of $f_{p}$ the value of $\tau\left(f_{p}\right)$ and thus of $\ln \tau\left(f_{p}\right)$ is fixed, and also $\tau\left(f_{p}\right)$ and thus $\ln \tau\left(f_{p}\right)$ increase monotonously with increasing $f_{p}$ (Eq. (A5)). Now consider Eq. (A6a). Since for a given annealing temperature the term $Q / R T$ is a constant, the data points in hypothetical plots of $\tau\left(f_{p}\right)$ or $\ln \tau\left(f_{p}\right)$ vs. $\ln \left(t-t_{\text {start }}\right)$ and thus also in acutally accessible plots of $f_{p}$ vs. $\ln \left(t-t_{\text {start }}\right)$ are located on sets of parallel ('isomorphous') curves which are shifted with respect to each other along the $\ln \left(t-t_{\text {start }}\right)$ axis, in accordance with the differences in $Q / R T$ caused by the differences in annealing temperature.

If an analytical description of $\ln \tau\left(f_{p}\right)+Q / R T$ is found for $0<t-t_{\text {start }}<\infty$ (either based on a suitable, physically motivated function for the time-dependence of $f_{p}$ or based on a phenomenological description, e.g. a polynomial (in $f_{p}$ ) approach as applied here (cf. Eq. (3)), the fit functions to the experimental data pertaining to the different annealing temperatures should differ by $f_{p}$-independent terms, e.g. $A_{0, T}$ (compare also Eq. (3)). Then an Arrhenius- 
type plot of $A_{0, T}$ vs. $1 / T$ yields a straight line with slope $+Q / R$ and an axis-intercept $a_{0}$ (see discussion in the second paragraph below Eq. (3)).

This type of analysis can also be performed directly on the basis of plots of $p\left(f_{p}\right) \mathrm{vs} . \ln (t$ $\left.-t_{\text {start }}\right)$, or on the basis of plots of $q$ vs. $\ln \left(t-t_{\text {start }}\right)$, where $q$ is an arbitrary bijective function of $f_{p}$, i.e. $q\left(f_{p}\right)$, and thus of $p$. Then Eq. (A4a) is expressed in terms of $p$ :

$\ln \tau(p)+Q /(R T)=\ln \left(t-t_{\text {start }}\right)$.

Eq. (A6b) can be rewritten in a similar way.

\section{Ex-situ isothermal annealing experiments}

In this case the parameter $p$ is measured at a reference temperature $T_{0}$ different from the annealing temperature $T$. The value of $p$ measured at this temperature is labelled with the index $T_{0}, p_{T_{0}}$. Thus the fraction transformed obtained by application of Eq. (A1) is labelled $f_{p_{T_{0}}}:$

$f_{p_{0}}\left(p_{T_{0}}\right)=\frac{p_{T_{0}}-p_{T_{0}, \text { start }}}{p_{T_{0}, \text { end }}-p_{T_{0}, \text { start }}}$

The strategy to measure $p$ at an annealing temperature-independent temperature $T_{0}$ is employed in ex-situ experiments where $T_{0}$ can correspond to ambient temperature (as in this work) or to another temperature at which the transformation rate is negligible and measurement of $p_{T_{0}}$ is easily feasible. In the present work $(c / a)_{0}$ takes the role of $p_{T_{0}}$ and $f_{(c / a)_{0}}$ that of $f_{p_{0}}$.

\section{In-situ isothermal annealing experiments}

In the course of in-situ experiments the parameter $p$ is not measured at a reference temperature $T_{0}$, but at different annealing temperatures. In that case analysis of the activation 
energy is, in principle, only possible, if the $T$-dependence of $p_{T}$ is known for the complete range of states the transformation runs through, so that the $T$ dependence of $p$ can be separated from the dependence of $p$ on the degree of the transformation.

The analysis can be kept simple if the selected measurable parameter $p_{T}$ depends only negligibly on $T$ for a given progress of transformation in a sufficiently narrow annealing (and measuring) temperature range $T_{\min } \leq T \leq T_{\max }$. Thus one can write $p_{T}=p_{T}$, where $\mathfrak{T}$ represents that temperature range. Then the fraction transformed can be written as

$$
f_{p_{\mathrm{T}}}=\frac{p_{\mathrm{T}}-p_{\mathrm{T}, \text { start }}}{p_{\mathrm{T}, \text { end }}-p_{\mathrm{T}, \text { start }}}
$$

where $p_{\mathrm{T}, \text { start }}$ and $p_{\mathrm{T} \text {,end }}$ are the values of $p_{\mathrm{T}}$ at the start and at the end of the transformation. However, even if the condition for applicability of Eq. (A9) mentioned above is valid, $f_{p_{\top}}$ does not necessarily need to be equal to a fraction transformed measured at a temperature outside the $T_{\min } \leq T \leq T_{\max }$ range for the same progress of transformation, e.g. to $f_{p_{T_{0}}}$. This last condition is met if linearity exists between $p_{\mathrm{T}}$ and $p_{T_{0}}$ according to Eq. (A2), since $p_{\mathrm{T}}$ and $p_{T_{0}}$ must be considered to be different parameters in the sense of Eq. (A2). In section 5.1 it is shown that this is the case for the $p_{\mathrm{T}}$ and $p_{T_{0}}$ employed in this work.

\section{References}

[1] J. I. Langford and D. Louër, Rep. Prog. Phys. 59131 (1996).

[2] M. C. Moron, J. Mater. Chem. 102617 (2000).

[3] H. M. Rietveld, J. Appl. Crystallogr. 265 (1969).

[4] J. Plevert, J. P. Auffredic, M. Louër, and D. Louër, J. Mater. Sci. 241913 (1989). 
[5] P. Ballirano, Caminiti, C. Ercolani, A. Maras, and M. A. Orrù, J. Am. Chem. Soc. 120 12798 (1998).

[6] U. Ruschewitz, C. Bähtz, and M. Knapp, Z. Anorg. Allg. Chem. 6291581 (2004).

[7] S. Brauer, J. O. Ström-Olsen, M. Sutton, Y. S.Yang, A. Zaluska, G. B. Stephenson, and U. Köster, Phys. Rev. B 457704 (1992).

[8] N. Audebrand, J.-P. Auffrédic, and D. Louër, Chem. Mater. 121791 (2000).

[9] O. Malis, and K. F. Ludwig Jr., Phys. Rev. B 6014675 (1999).

[10] P. van Mourik, E. J. Mittemeijer, and Th. H. de Keijser, J. Mater. Sci. 182706 (1983).

[11] P. van Mourik, N. M. Maaswinkel, Th. H. de Keijser, and E. J. Mittemeijer, J. Mater. Sci. 243779 (1989).

[12] E. J. Mittemeijer in Analytical Characterization of Aluminum, Steel and Superalloys (Eds. D. S. MacKenzie and G. E. Totter) CRC Taylor \& Francis, Boca Raton, 2006, pp. 339354.

[13] P. Nash and A. Nash, Bull. Alloy Phase Diagr. 6350 (1985).

[14] C. Schmetterer, H. Flandorfer, K. W. Richter, U. Saeed, M. Kauffman, P. Roussel, H. Ipser, submitted for publication.

[15] A.-K. Larsson, R. L. Withers, and L. Stenberg, J. Solid State Chem. 127222 (1996).

[16] A. Leineweber, O. Oeckler, and U. Zachwieja, J. Solid State Chem. 177936 (2004).

[17] A. Leineweber, M. Ellner, E.J. Mittemeijer, J. Solid State Chem. 159191 (2001).

[18] A. Leineweber, J. Solid State Chem. 1771197 (2004).

[19] A. Leineweber, and E. J. Mittemeijer, Z. Anorg. Allg. Chem. 6282147 (2004).

[20] E. J. Sonneveld and R. Delhez, 'ProFit' Version 1.0c. Philips Electronics N.V. (1996).

[21] B. H. Toby, CMPR - package of programs, National Institute of Standards; http://www.ncnr.nist.gov/xtal (2000).

[22] L. W. Finger, D. E. Cox, and A. P. Jephcoat, J. Appl. Crystallogr. 27892 (1994).

[23] K. Koths, ASIN, version 7.4, University of Dortmund (1987). 
[24] M. Knapp, V. Joco, C. Bähtz, H.H. Brecht, A. Berghäuser, H. Ehrenberg, H. von Seggern, and H. Fuess, Nucl. Instrum. Meth. A 521565 (2004).

[25] A. Leineweber, E. J. Mittemeijer, M. Knapp, and C. Baehtz, Mater. Sci. Forum 443-444 247 (2004).

[26] J. Burke, The Kinetics of Phase Transformations in Metals, Pergamon Press, Oxford, UK (1965).

[27] E. J. Mittemeijer, J. Mater. Sci. 273977 (1992).

[28] A. Leineweber, F. Krumeich, E. J. Mittemeijer et al. to be published.

[29] K. Schubert, Kristallstrukturen zweikomponentiger Phasen, Springer (1964).

[30] A. Leineweber, M. Knapp, C. Baehtz, unpublished.

[31] P. D. Pathak and N. G. Vasvada, Acta Crystallogr. A 26655 (1970).

[32] C. Baehtz, M. Knapp, unpublished.

[33] W. A. Soffa and D. E. Laughlin, Acta Metall. 373019 (1989).

[34] H. Wondratschek and W. Jeitschko, Acta Crystallogr. A 32664 (1976).

[35] Y.-Q. Sun, Structure of Antiphase Boundaries and Domains, Ch. 21 in: Westbrook, J.H. and Fleischer, R. L.: Intermetallic Compounds. New York: J. Wiley (1994), p. 495.

[36] H. Schmidt, G. Frohberg, and H. Wever, Acta Metall. Mater. 403105 (1992).

[37] G. F. Zhou, L. M. Di, and H. Bakker, J. Appl. Phys. 731521 (1993).

[38] F. Liu, F. Sommer, E. J. Mittemeijer, J. Mater. Sci. 391621 (2004). 
Tables

Table 1: Lattice parameters of the different, initial HT-Ni ${ }_{1.50} \mathrm{Sn}$ batches used in the present study, as well as of the reference LT-Ni ${ }_{1.50} \mathrm{Sn}$ prepared from HT1 by annealing for $5 \mathrm{~d}$ at 673 $\mathrm{K}$ followed by quenching, representing the end state of the phase transformation (see Figure 1)

\begin{tabular}{lcccccc}
\hline batch & $a_{\mathrm{HT}}, a_{\mathrm{LT}} / 2(\AA)$ & $b_{\mathrm{LT}}(\AA)$ & $c_{\mathrm{HT}}, c_{\mathrm{LT}}(\AA)$ & $c / a,(c / a)_{\mathrm{eff}}^{\mathrm{a}}$ & orth dist $^{\mathrm{b}}$ & Volume $\left.\AA^{3}\right)$ \\
\hline $\mathrm{HT} 1$ & $4.1045(3)$ & - & $5.1831(4)$ & 1.2628 & 0 & 75.62 \\
$\mathrm{HT} 2$ & $4.1049(2)$ & - & $5.1826(2)$ & 1.2625 & 0 & 75.63 \\
$\mathrm{HT} 3$ & $4.1041(5)$ & - & $5.1836(5)$ & 1.2630 & 0 & 75.61 \\
$\mathrm{LT}$ & $4.0770(3)$ & $7.1247(4)$ & $5.1954(3)$ & $1.2687^{\mathrm{a}}$ & 0.0089 & $75.46^{\mathrm{c}}$ \\
${ }^{\mathrm{a}} c_{\mathrm{LT}} /\left(a_{\mathrm{LT}} b_{\mathrm{LT}} /\left(2 \cdot 3^{1 / 2}\right)\right)^{1 / 2}=c_{\mathrm{LT}} / a_{\mathrm{eff}}$ & & & & \\
${ }^{\mathrm{b}}{ }_{2} b_{\mathrm{LT}} /\left(3^{1 / 2} a_{\mathrm{LT}}\right)-1$ & & & & & \\
${ }^{\mathrm{c}} V_{\mathrm{LT}} / 2$
\end{tabular}


Table 2. Key parameters derived from/valid for the in-situ powder diffraction experiments (three hightemperature runs)

\begin{tabular}{|c|c|c|c|c|}
\hline $\begin{array}{l}\text { lattice parameters } \\
\mathrm{HT}-\mathrm{Ni}_{1.50} \mathrm{Sn}(\mathrm{ex}-\mathrm{situ} \\
\text { experiments; cf. Table } 1)\end{array}$ & $\begin{array}{l}a(\AA) \\
c(\AA) \\
c / a\end{array}$ & \multicolumn{3}{|c|}{$\begin{array}{l}4.1045 \\
5.1831 \\
1.2628\end{array}$} \\
\hline $\begin{array}{l}\text { measured lattice parameter of } \\
\mathrm{NaCl}\end{array}$ & $a(\AA)$ & 5.6398 & 5.6399 & 5.6399 \\
\hline $\begin{array}{l}\text { temperature derived from } \\
\text { a }(\mathrm{NaCl}) \text { using Eq. }(1) \\
\text { (actual temperature) }\end{array}$ & $T(\mathrm{~K})$ & 291 & 292 & 292 \\
\hline \multicolumn{5}{|l|}{ high temperature measurements } \\
\hline $\begin{array}{l}\text { nominal temperature of high } \\
\text { temperature run }\end{array}$ & $T(\mathrm{~K})$ & 533 & 543 & 558 \\
\hline $\begin{array}{l}\text { time of the start of first } \\
\text { measurement }^{\text {a }}\end{array}$ & $\begin{array}{l}t-t_{\text {start }} \\
(\mathrm{min})\end{array}$ & 1 & 16 & 1 \\
\hline $\begin{array}{l}\text { actual temperature of first } \\
\text { measurement from } a(\mathrm{NaCl}) \\
\text { using Eq. (1) }\end{array}$ & $T(\mathrm{~K})$ & 511 & 527 & 539 \\
\hline total no. of measurements & & 43 & 33 & 26 \\
\hline $\begin{array}{l}\text { time average of the measured } \\
\text { lattice parameters of } \mathrm{NaCl}\end{array}$ & $a(\AA)^{\mathrm{b}}$ & $5.6950(3)$ & $5.6979(2)$ & $5.7015(3)$ \\
\hline $\begin{array}{l}\text { temperature derived from } \\
a(\mathrm{NaCl}) \text { using Eq. (1) } \\
\text { (actual temperature) }\end{array}$ & $T(\mathrm{~K})^{\mathrm{c}}$ & $516(1)$ & $527(1)$ & $541(1)$ \\
\hline $\begin{array}{l}\text { difference between nominal } \\
\text { temperature and actual } \\
\text { temperature from } a(\mathrm{NaCl})\end{array}$ & $\Delta T(\mathrm{~K})$ & 17 & 16 & 17 \\
\hline $\begin{array}{l}\text { temperature estimated from } \\
\text { comparison with ex-situ } \\
\text { kinetics }^{\mathrm{d}}\end{array}$ & $T(\mathrm{~K})$ & 520 & 528 & 543 \\
\hline $\begin{array}{l}\text { ranges of observed }(c / a)_{\mathfrak{T}} \text { and } \\
\text { annealing time }\end{array}$ & & $\begin{array}{c}1.2637 \\
(1 \mathrm{~min}) \\
1.2671 \\
(918 \mathrm{~min})\end{array}$ & $\begin{array}{c}1.2644 \\
(16 \mathrm{~min}) \\
1.2670 \\
(412 \mathrm{~min})\end{array}$ & $\begin{array}{c}1.2642 \\
(1 \mathrm{~min}) \\
1.2672 \\
(159 \mathrm{~min})\end{array}$ \\
\hline
\end{tabular}

final pattern (ambient temperature; nominal temperature 294-295 K)

\begin{tabular}{|l|c|c|c|c|}
\hline lattice parameters & $a(\AA)$ & 4.0987 & 4.0992 & 4.0989 \\
$\mathrm{Ni}_{1.50} \mathrm{Sn}$ & $c(\AA)$ & 5.1907 & 5.1907 & 5.1903 \\
& $c / a$ & 1.2664 & 1.2662 & 1.2663 \\
\hline lattice parameter of $\mathrm{NaCl}$ & $a(\AA)$ & 5.6397 & 5.6400 & 5.6399 \\
\hline temperature derived from & $T(\mathrm{~K})$ & 291 & 292 & 292 \\
$a(\mathrm{NaCl})$ using Eq. (1) & & & & \\
\hline
\end{tabular}

a) i.e. the time passed after setting the furnace at the final nominal temperature.

b) standard deviation as indicated pertains to the $a(\mathrm{NaCl})$ values obtained from all measurements of a high temperature run.

c) standard deviation of the temperature corresponding to the standard deviation of $a(\mathrm{NaCl})$

d) see section 5.1 


\section{Figure captions}

Figure 1: X-ray powder diffraction patterns of reference HT-Ni $1_{1.50} \mathrm{Sn}$ and reference LT$\mathrm{Ni}_{1.50} \mathrm{Sn} . h k l$ values of reflections have been given with respect to the hexagonal lattice of the HT phase, superstr. indicates superstructure reflections characteristic for the long-range ordered (Ni(2) atoms) LT phase. For better visibility of the different patterns different offsets along the ordinate were used. $h k l$ indices refer to the HT phase.

Figure 2: Evolution of the diffraction patterns as a function of the progress of transformation upon annealing of quenched (disordered) $\mathrm{HT}-\mathrm{Ni}_{1.50} \mathrm{Sn}$ establishing LT-Ni $\mathrm{H}_{1.50} \mathrm{Sn}$ below the equilibrium (ordered) LT $\square \quad$ (disordered) HT transition temperature (790 K): 1st stage (a) characterised by increase of $c / a$ and the emergence of the superstructure reflections; 2 nd stage (b) characterised by coarsening of the ordered domains (sharpening of the superstructure reflections) and splitting of fundamental reflections in correspondence with the orthorhombic distortion of LT with respect to HT. The reflection group emanating from the 110 reflection of the HT phase is shown enlarged at the right. For better visibility of the different patterns different offsets along the ordinate were used. $h k l$ indices refer to the HT phase.

Figure 3: X-ray diffraction pattern recorded using synchrotron radiation (wavelength: 0.70952 $\AA$ ) and a stationary imaging plate system at the beam line B2 (HASYLAB, Hamburg, D). Data was collected from a $0.3 \mathrm{~mm}$ diameter capillary sample of $\mathrm{Ni}_{1.50} \mathrm{Sn}+\mathrm{NaCl}$ (as temperature calibrant) with an exposure time of $2 \mathrm{~min}$. Such patterns were used for the in-situ observation of the annealing-time and annealing-temperature dependent evolution of the axial ratio $c / a$ of the (pseudo-)hexagonal $\mathrm{Ni}_{1.50} \mathrm{Sn}$. Markers indicate the positions of $\mathrm{Ni}_{1.50} \mathrm{Sn}$ and $\mathrm{NaCl}$ reflections. $h k l$ indices refer to the $\mathrm{HT}-\mathrm{Ni}_{1.50} \mathrm{Sn}$ phase phase. 
Figure 4: Plot of the hexagonal lattice parameters $c$ vs. $a$ from the annealing-time resolved powder diffraction data (solid symbols). The arrows indicate the 'direction' of change $(\mathrm{HT} \rightarrow \mathrm{LT})$ with advancing progress of transformation: (a) Ex-situ data (filled symbols) together with data points (open symbols; note that the open triangle of the HT1 data point coincides with a filled triangle corresponding to a $510 \mathrm{~K}$ data point) for the two different, initial HT phase batches used as starting materials and the reference (end stage) LT-Ni $i_{1.50} \mathrm{Sn}$ sample (plotting $c_{\text {LT }}$ vs. $a_{\text {eff }}$ for orthorhombic LT ; cf. Table 1). The data shown were recorded at $296 \mathrm{~K}$ (cf. section 2.4). (b) In-situ data (cf. section 2.5; filled symbols), including results (open symbols) from high-temperature in-situ powder diffraction on well-ordered (end stage) LT-Ni ${ }_{1.50} \mathrm{Sn}[30]$, plotting $c_{\mathrm{LT}}$ vs. $a_{\text {eff }}$; the interconnecting line has been drawn to guide the eye.

Figure 5: Evolution of $c / a$ of (initially HT) $\mathrm{Ni}_{1.50} \mathrm{Sn}$ as a function of the annealing-time $t-t_{\text {start }}$ (see text for the temperatures indicated; the lines have been drawn to guide the eye.): (a) Exsitu data with all $(c / a)_{0}$ as measured at $296 \mathrm{~K}$ (cf. section 2.4$)$. The effective $c / a\left(=c_{\mathrm{LT}} / a_{\mathrm{eff}}\right)$ of end stage (equilibrated at $673 \mathrm{~K}$ ) LT-Ni ${ }_{1.50} \mathrm{Sn}$ has been indicated too. (b) In situ data with all $(c / a)_{\mathfrak{T}}$ at indicated (actual) annealing temperatures in the range 516-541 K (cf. section 2.5). The effective $c / a$ of equilibrium $\mathrm{LT}-\mathrm{Ni}_{1.50} \mathrm{Sn}$ in this temperatures range is roughly 1.270 (see Figure 4b).

Figure 6: The fraction transformed $f$ and the axial ratio $c / a$ vs. the logarithm of the annealing time period, $\ln \left(t-t_{\text {start }}\right)$, for the various annealing temperatures as derived from the $c$ and $a$ lattice-parameter measurements. The curves observed for the different annealing temperatures are 'isomorphous' and shifted with respect to each other along the abscissa. (a) Ex-situ data of axial ratios measured at ambient temperatures, $(c / a)_{0}$, leading to $f_{(c / a)_{0}}$ using Eq. (2). (b) Insitu data of axial ratios measured at the respective annealing temperatures, $(c / a)_{\mathfrak{T}}$, leading to 

5.1). The curves drawn correspond to the fits according to Eq. (3) (a) and Eq. (7) (b) for the fraction-transformed ranges indicated by the perpendicular double arrows.

Figure 7: Arrhenius-type plots yielding the activation energies from the slope, (a) ex-situ data, (b) in-situ data (cf. Eq. (3) and discussion). 


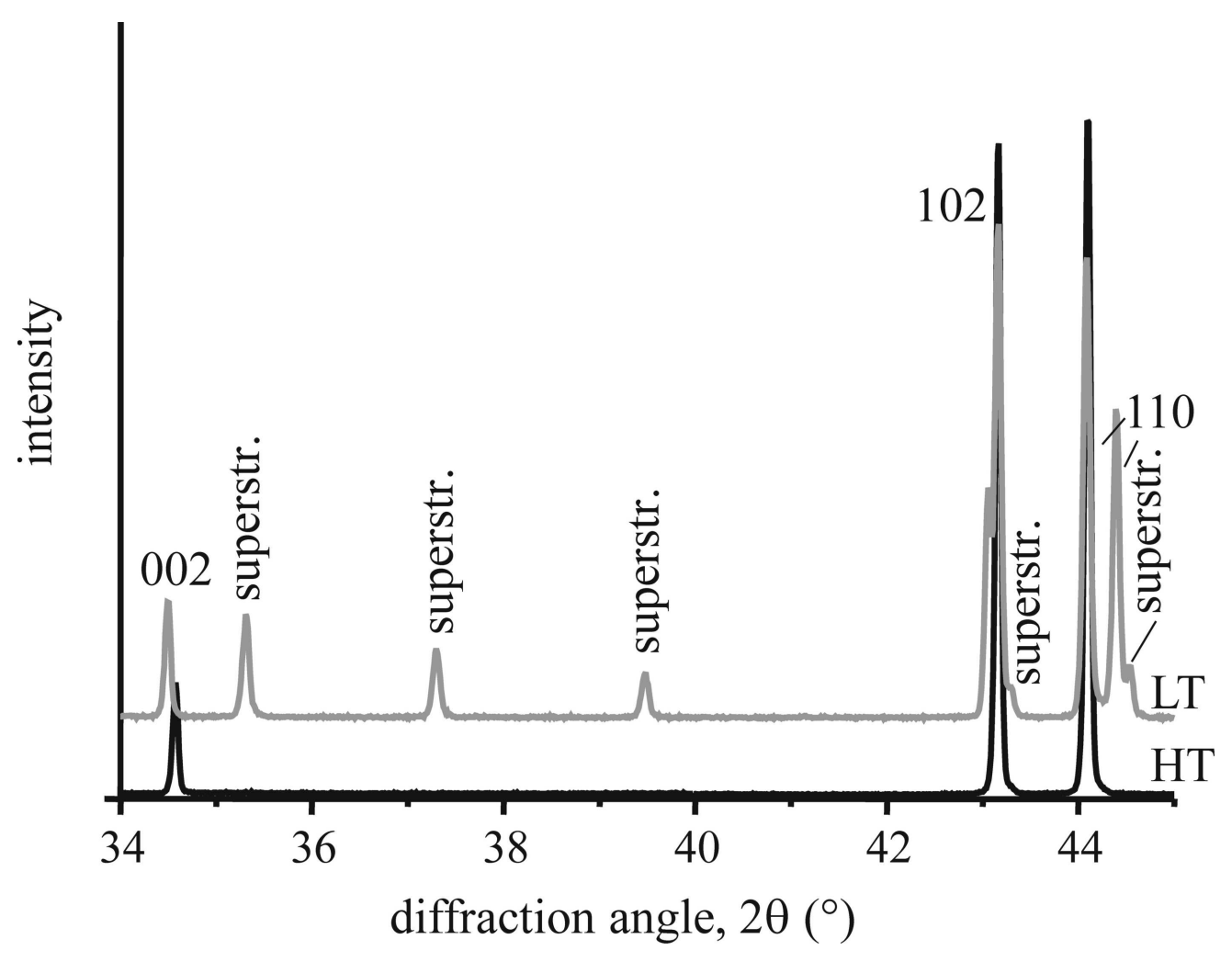

Figure 1 $119 \times 91 \mathrm{~mm}(600 \times 600 \mathrm{DPI})$ 


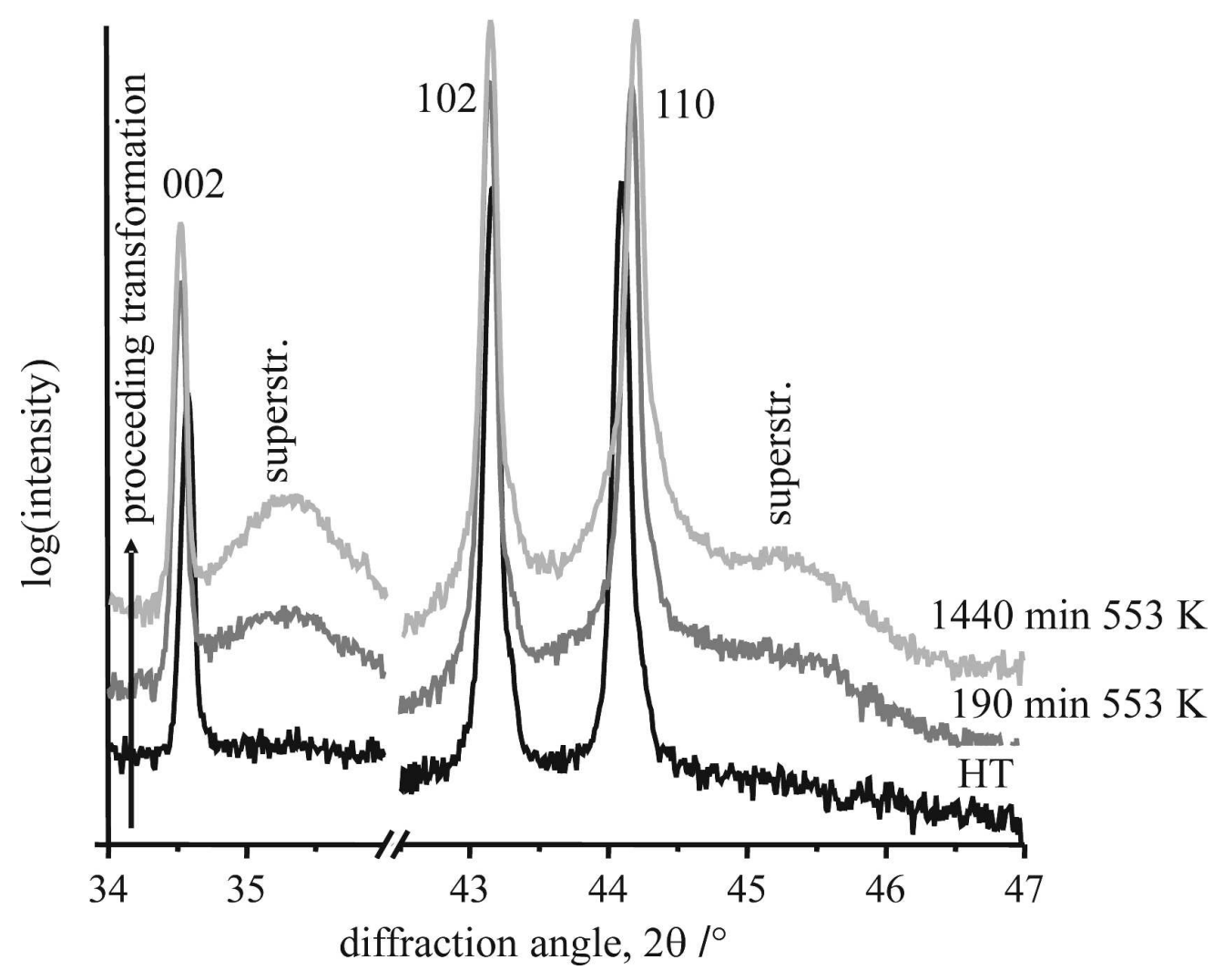

Figure $2 a$

$142 \times 115 \mathrm{~mm}(600 \times 600$ DPI $)$ 


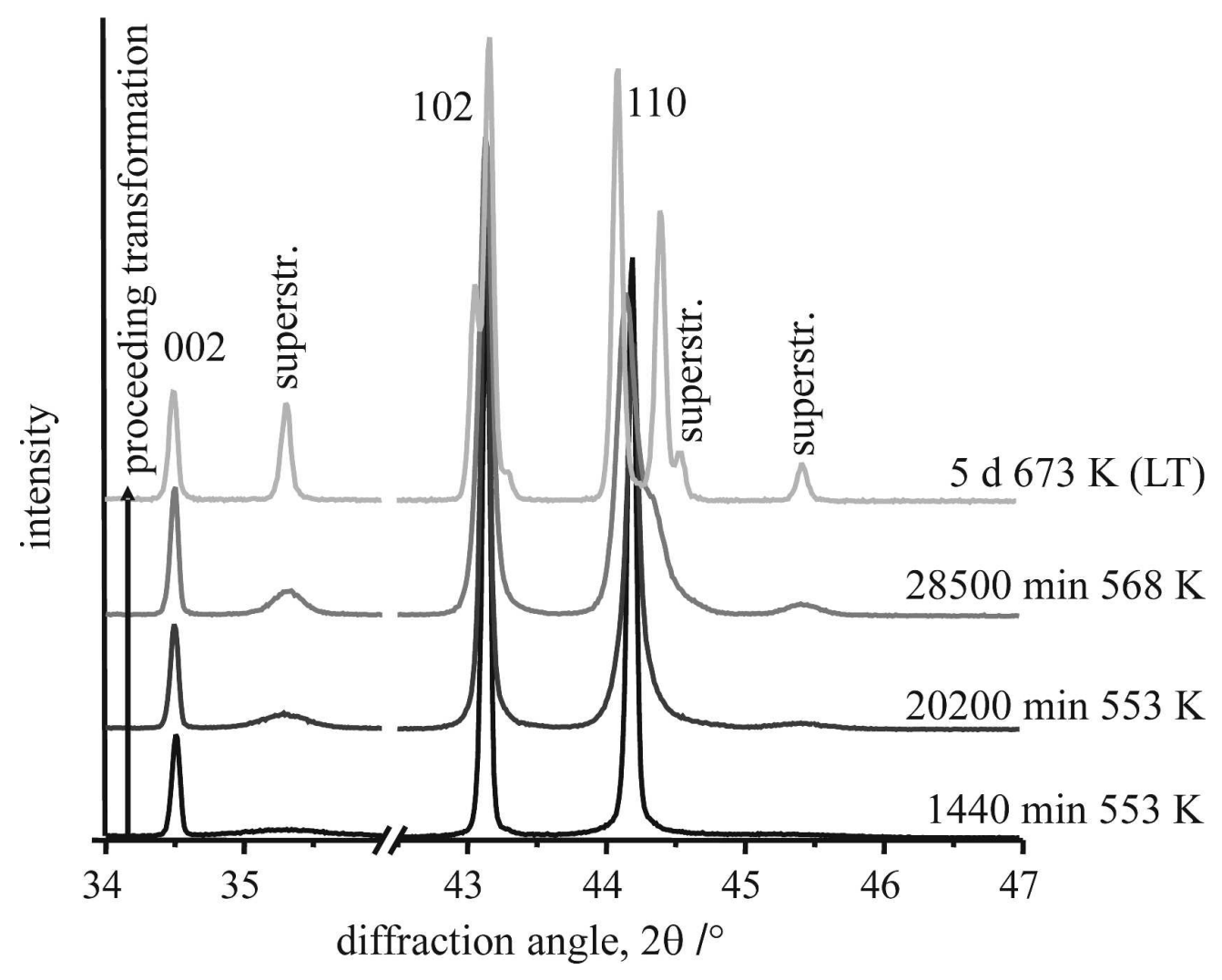

Figure $2 b$

$142 \times 114 \mathrm{~mm}(600 \times 600 \mathrm{DPI})$ 


1
2
3
4
5
6
7
8
9
10
11
12
13
14
15
16
17
18
19
20
21
22
23
24
25
26
27
28
29
30
31
32
33
34
35
36
37
38
39
40
41
42
43
40
45
49
50
51
52
53
55
50

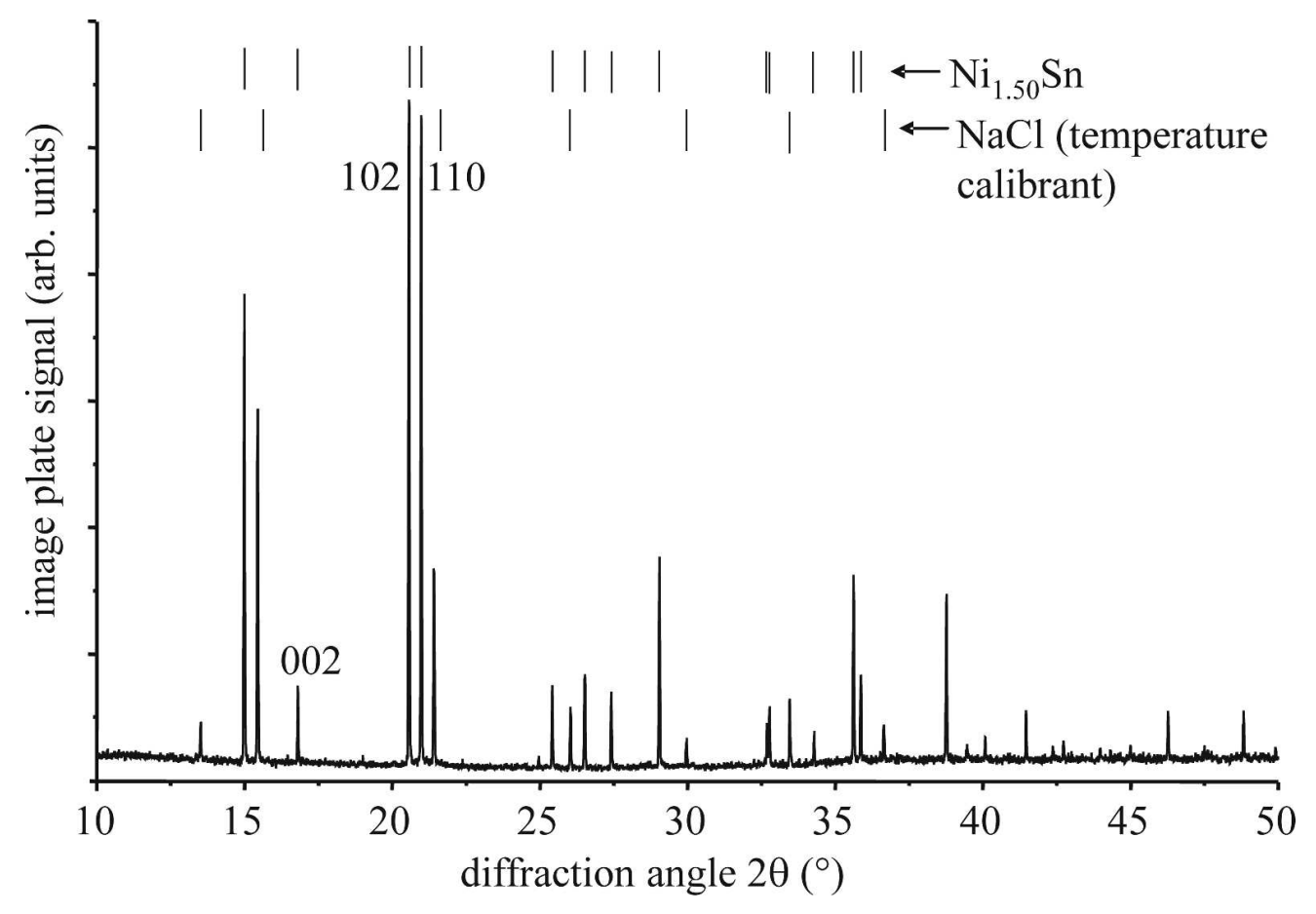

Figure 3 $133 \times 92 \mathrm{~mm}(600 \times 600 \mathrm{DPI})$ 


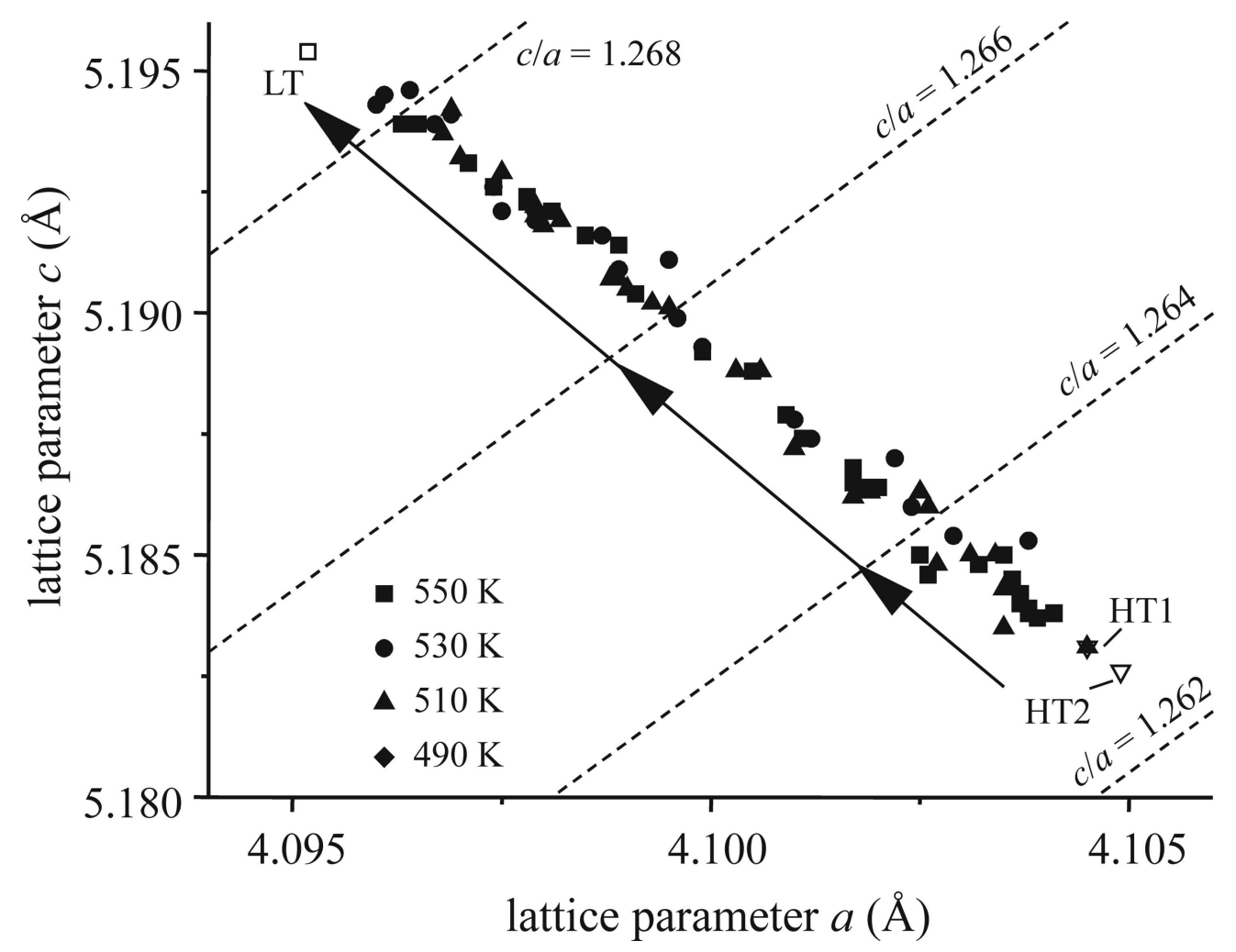

Figure $4 a$

$124 \times 96 \mathrm{~mm}(600 \times 600 \mathrm{DPI})$ 


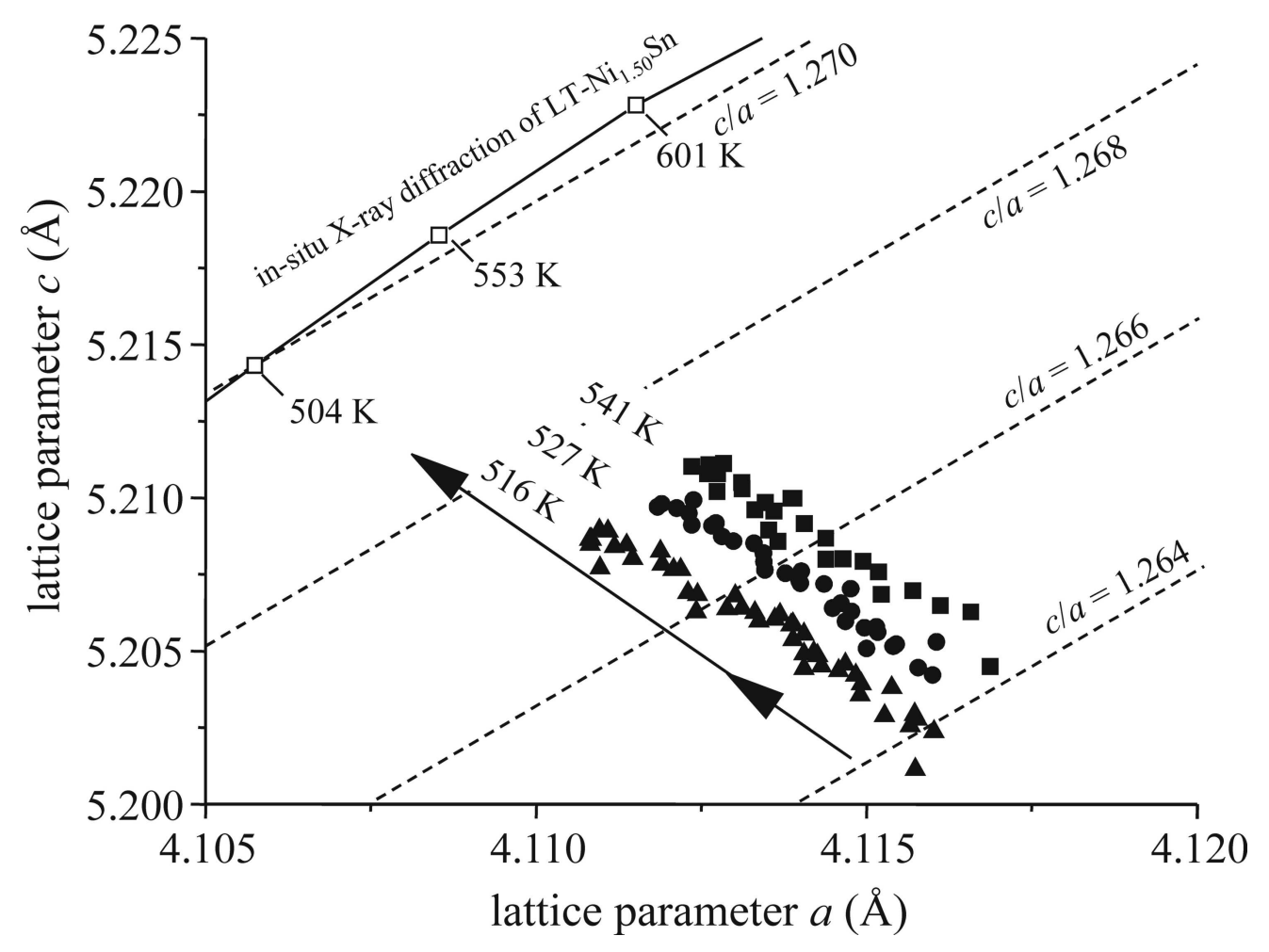

Figure $4 b$

$125 \times 93 \mathrm{~mm}(600 \times 600$ DPI $)$ 


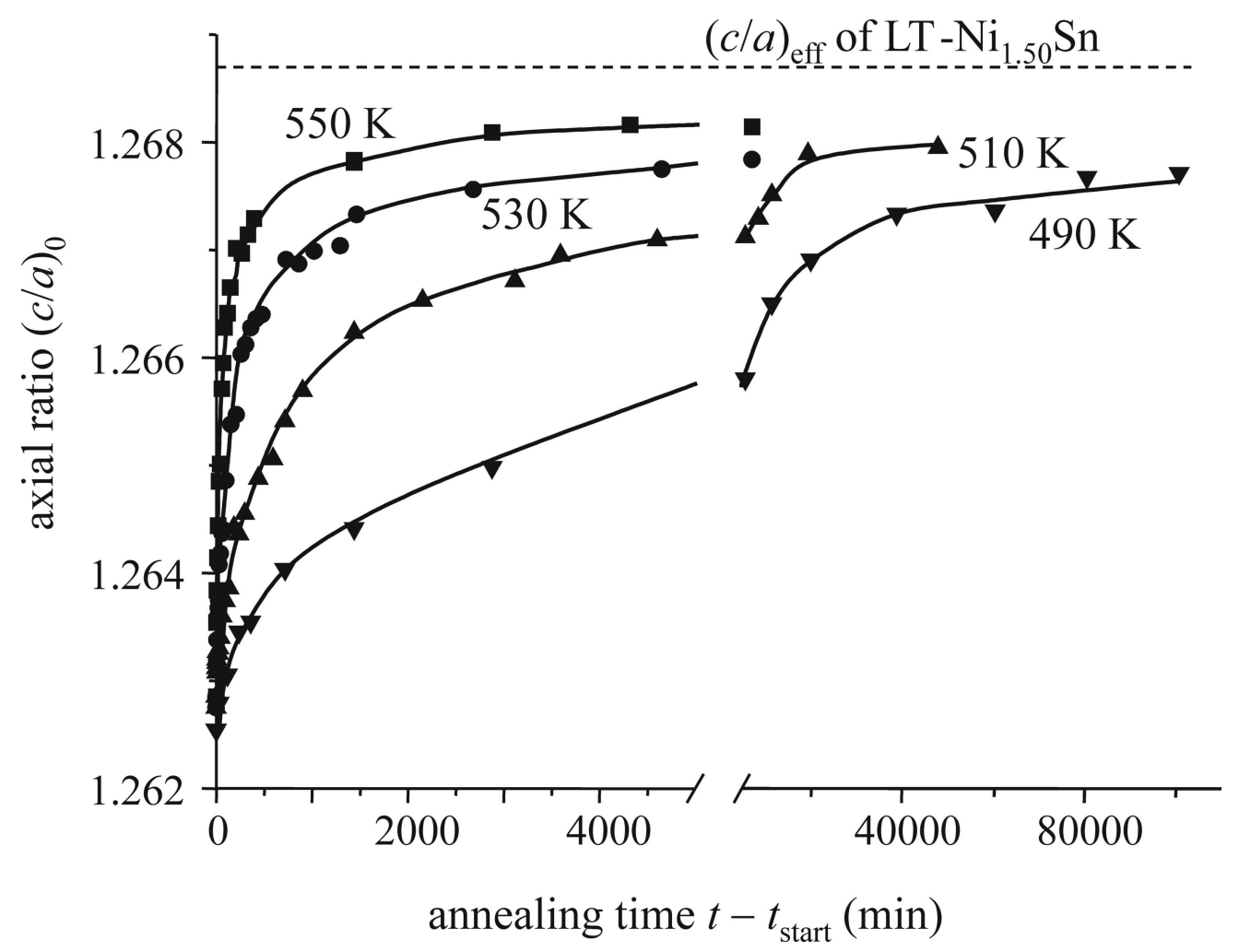

Figure $5 a$

$129 \times 99 m m(600 \times 600$ DPI $)$ 


1
2
3
4
5
6
7
8
9
10
11
12
13
14
15
16
17
18
19
20
21
22
23
24
25
26
27
28
29
30
31
32
33
34
35
36
37
38
39
40
41
42
43
40
45
49
50
51
52
53
55
50

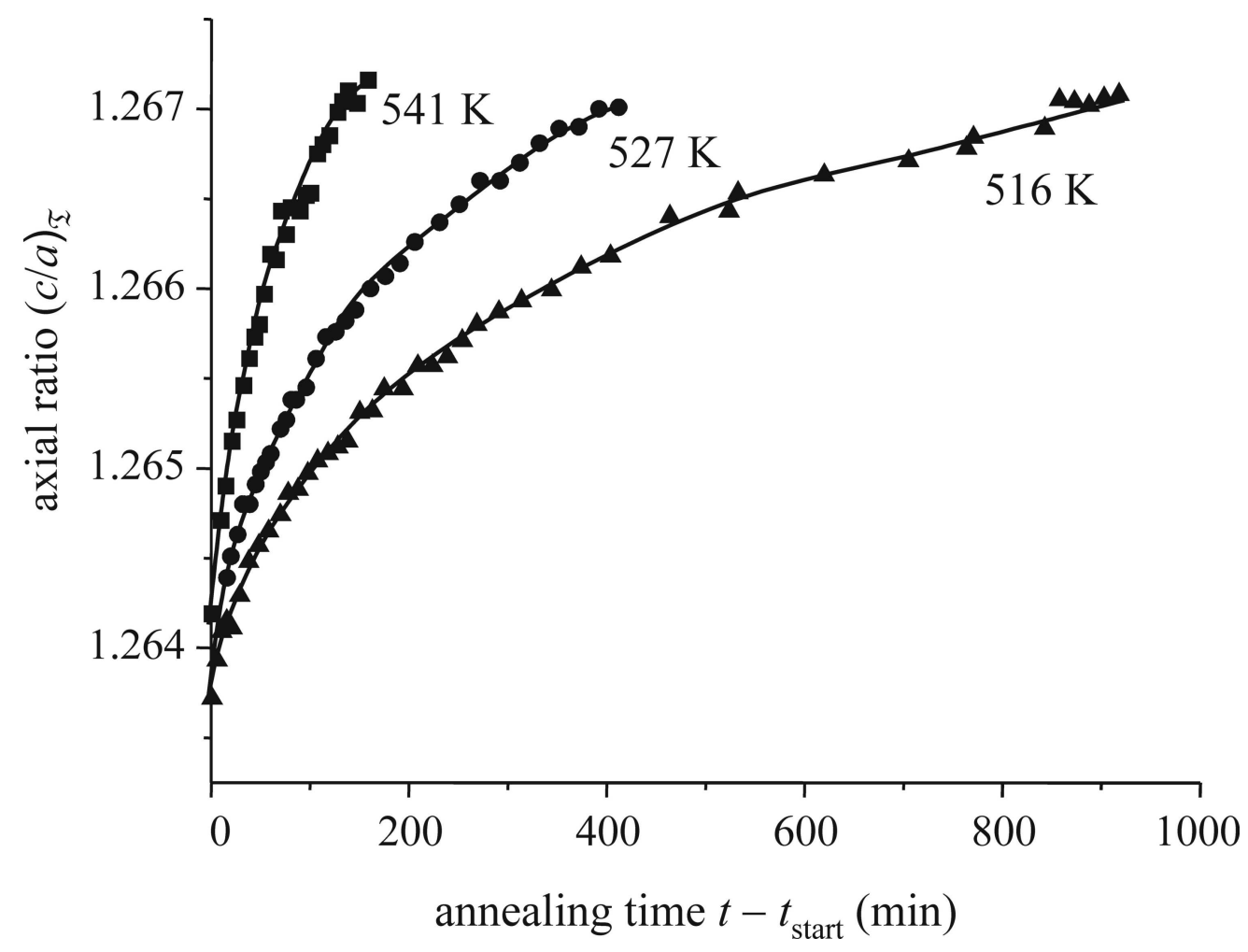

Figure $5 b$

$127 \times 96 \mathrm{~mm}(600 \times 600 \mathrm{DPI})$ 


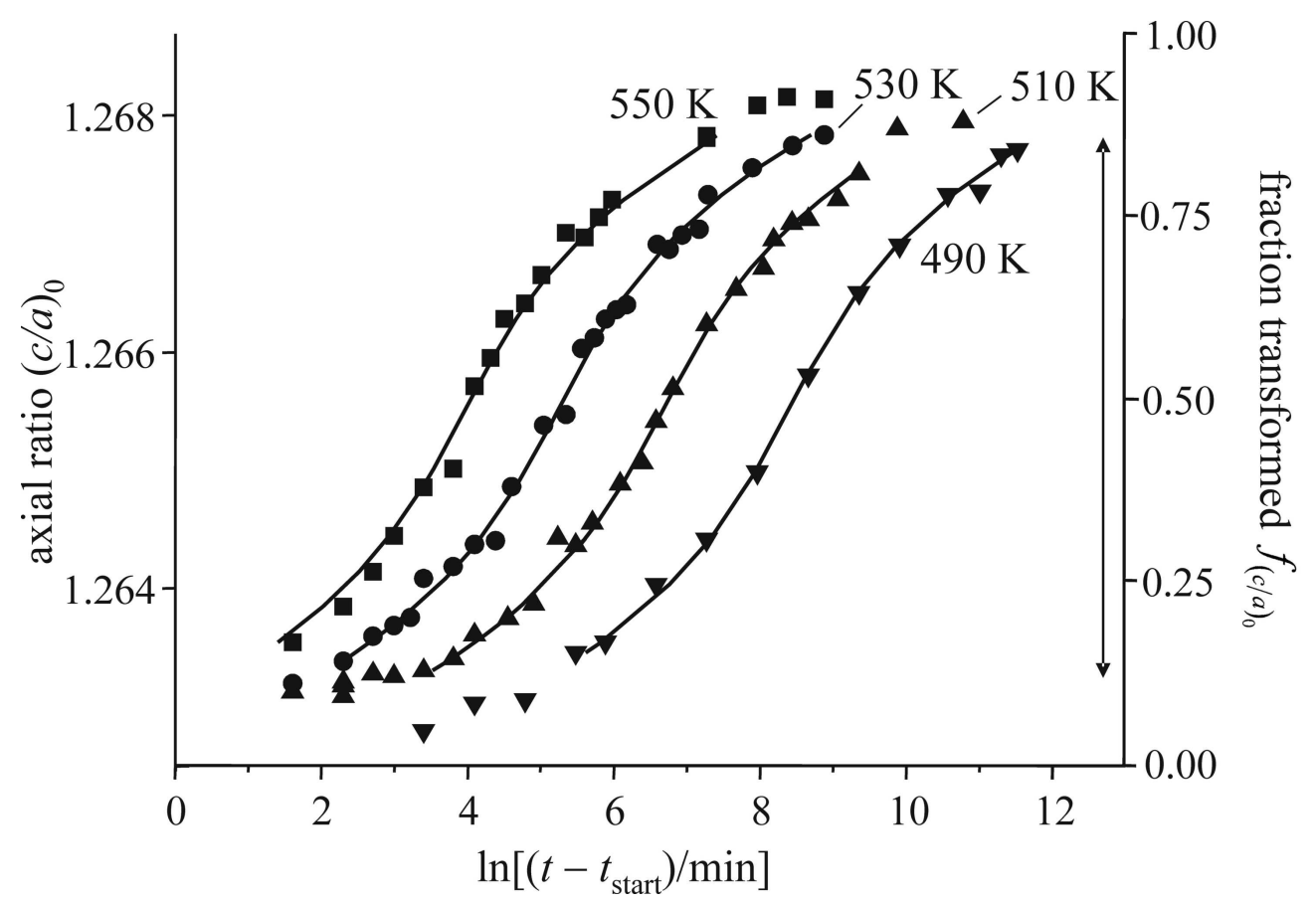

Figure $6 a$

$125 \times 84 \mathrm{~mm}(600 \times 600 \mathrm{DPI})$ 


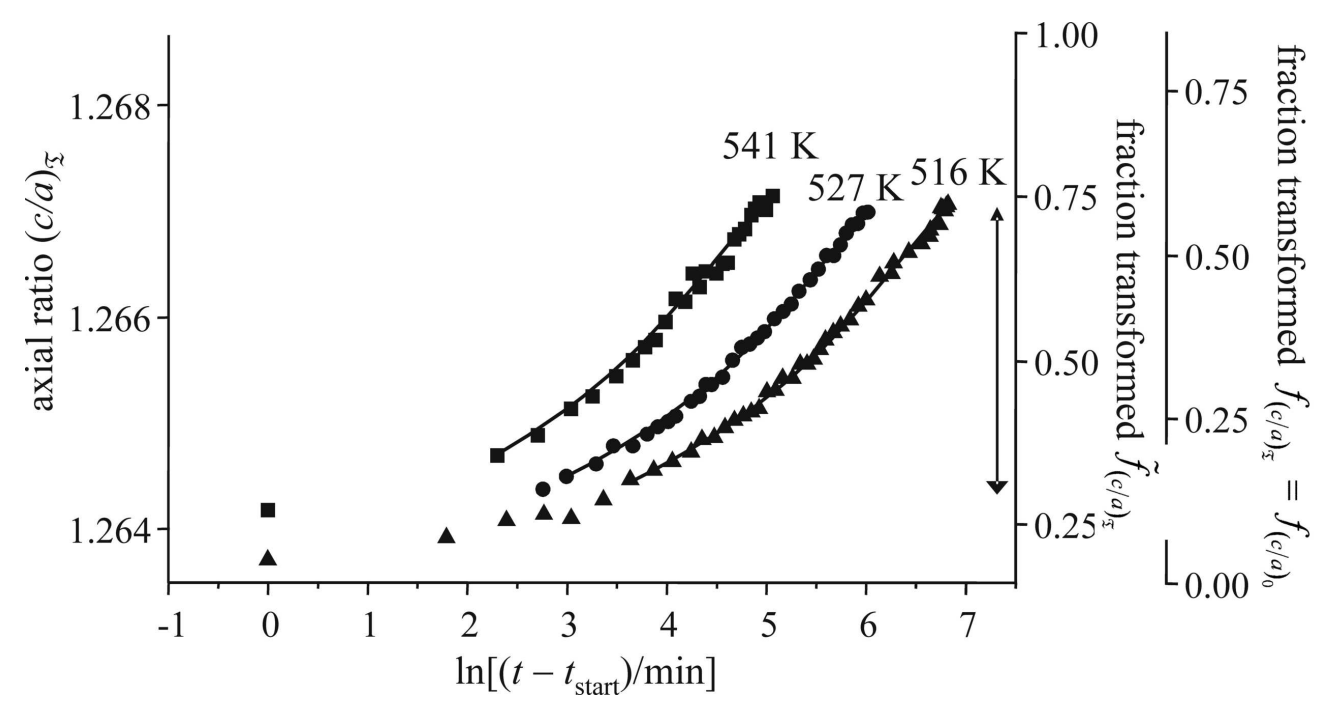

Figure $6 \mathrm{~b}$

$108 \times 55 \mathrm{~mm}(600 \times 600 \mathrm{DPI})$ 


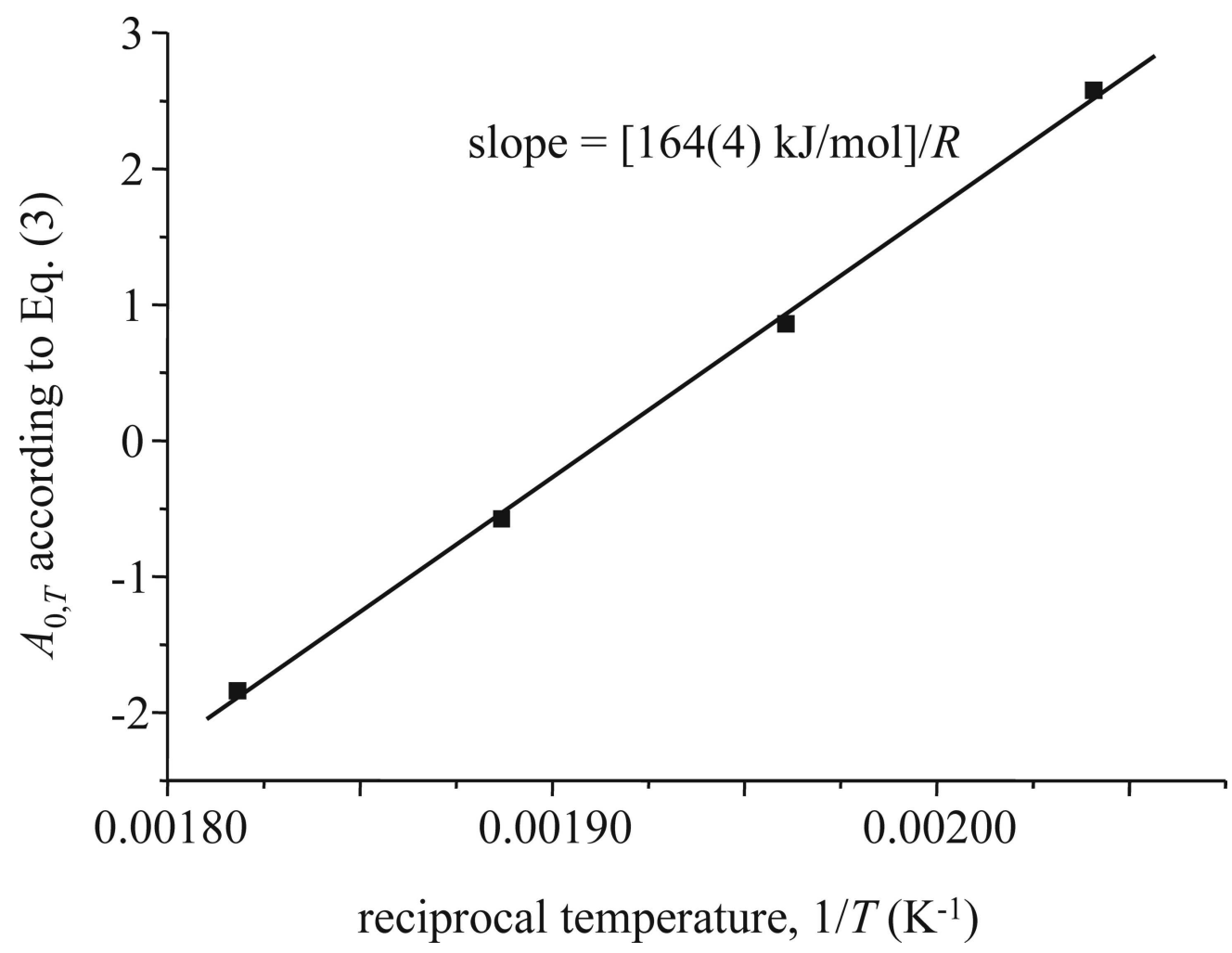

Figure $7 a$

$123 \times 94 \mathrm{~mm}(600 \times 600 \mathrm{DPI})$ 


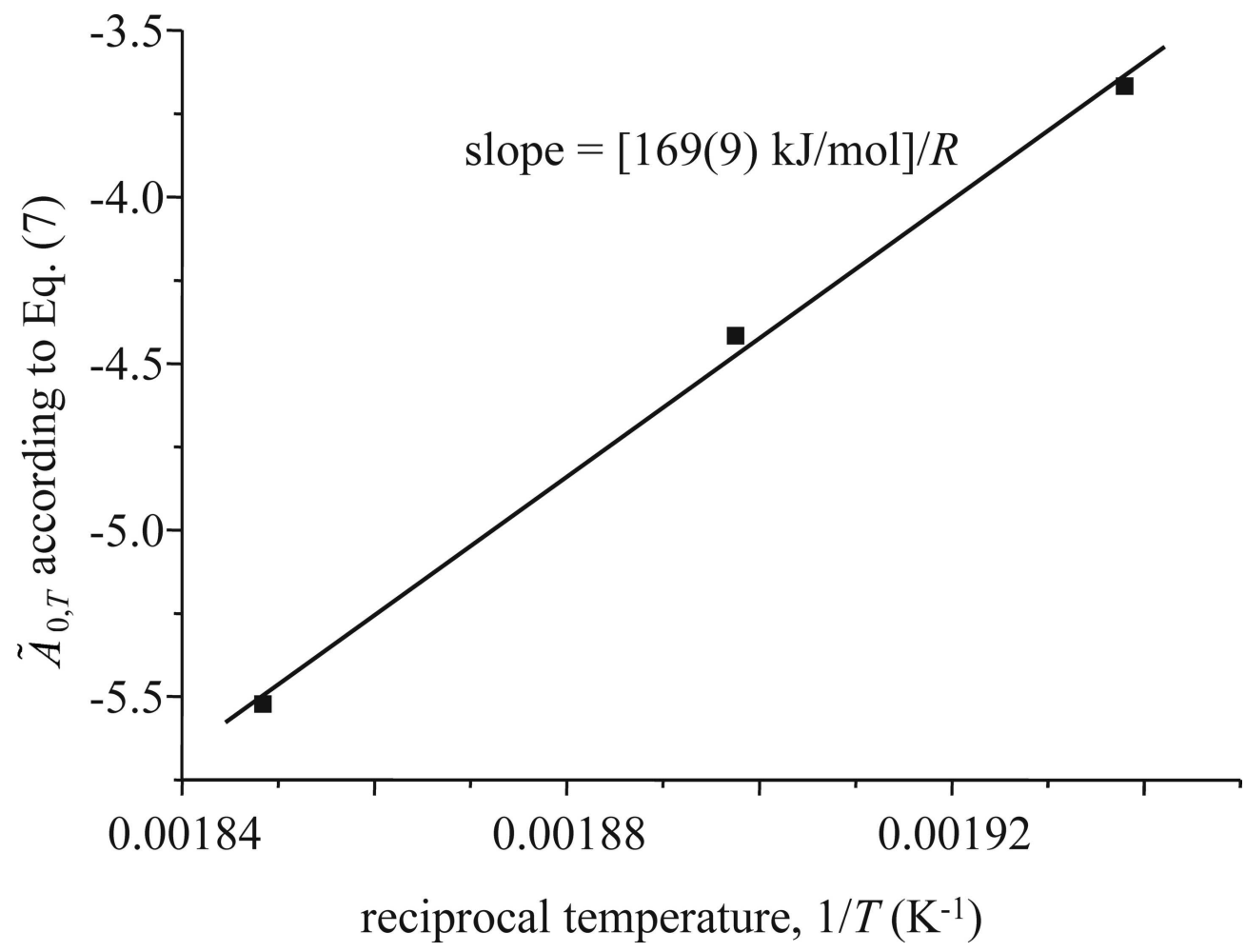

Figure $7 b$ $123 \times 92 \mathrm{~mm}(600 \times 600$ DPI $)$ 